\title{
Three-dimensional analysis of unlined tunnels in rock subjected to high horizontal stress
}

\author{
M. Abdel-Meguid, R.K. Rowe, and K.Y. Lo
}

\begin{abstract}
An analysis of the stability of underground openings in weak rock is important to the design of the support requirements near the tunnel face. A detailed three-dimensional (3D) elastoplastic finite element study of face stability and the corresponding stresses around the face is conducted for a large-diameter tunnel in southern Ontario. The effect of the rock mass strength and high horizontal stresses on the tunnel deformation, stability, and distribution of tangential stresses at the tunnel circumference is investigated. To facilitate comparison with plane strain analysis, 3D results are presented for several cross sections across the tunnel. The effect of tunnel construction sequence on the predicted results is discussed.
\end{abstract}

Key words: weak rock, tunnelling, horizontal stresses, three-dimensional, finite element, excavation, face stability, modeling.

Résumé : Une analyse de la stabilité d'ouvertures souterraines dans la roche molle est importante pour la conception des exigences de soutènement près de la face du tunnel. On a réalisé une étude détaillée tridimensionnelle élastoplastique par éléments finis de la stabilité de la face et des contraintes correspondantes autour de la face pour un tunnel de grand diamètre dans le sud de l'Ontario. On a étudié l'effet de la résistance de la masse rocheuse et des fortes contraintes horizontales sur la déformation du tunnel, de même que la stabilité et la distribution des contraintes tangentielles à la circonférence du tunnel. Pour faciliter la comparaison avec une analyse en déformation plane, on présente les résultats 3D pour plusieurs sections en travers du tunnel. On discute l'effet de l'ordre de la succession des travaux de construction du tunnel sur les résultats prédits.

Mots clés : roche molle, creusage de tunnel, contraintes horizontales, tridimensionnel, éléments finis, excavation, stabilité de la face, modélisation.

[Traduit par la Rédaction]

\section{Introduction}

When an underground opening is excavated into a stressed rock mass, the stresses in the vicinity of the opening are redistributed such that the tangential stresses are maximum at the periphery of the excavation and decrease with an increase in the distance from the tunnel. Therefore, the rock may yield in the overstressed zone surrounding the excavation. Closed-form solutions for calculating the stress distribution provide a conceptual understanding of behaviour and are useful for testing and calibrating numerical models. However, these solutions are restricted to plane strain analysis of simple geometries and material models.

It is known that the ground behaviour near the face of an advancing tunnel is a problem that cannot be analyzed by

Received 17 October 2002. Accepted 28 July 2003. Published on the NRC Research Press Web site at http://cgj.nrc.ca on 17 November 2003.

M.A. Abdel-Meguid and R.K. Rowe. ${ }^{1}$ Department of Civil Engineering, Queens University, Kingston, ON K7L 3N6, Canada.

K.Y. Lo. Geotechnical Research Centre, Department of Civil Engineering, University of Western Ontario, London,

ON N6A 5B9, Canada.

${ }^{1}$ Corresponding author (e-mail: kerry@ civil.queensu.ca). closed-form solutions or by simplified plane strain or axisymmetric finite element models. Several authors (Sakurai 1983; Lo et al. 1992; Hoek and Marinos 1998; and others) have addressed the problem of face stability of tunnels in weak rock. Lo et al. (1984) presented a theoretical elastic solution for stresses and displacements during the face advance. Lo et al. (1992) utilized the results of elastoplastic axisymmetric finite element analysis together with a plane strain closed-form solution to introduce the concept of load sharing ratio between the rock mass at the tunnel face and the supporting system. A fictitious support pressure was considered in their analysis by gradually reducing the initial radial stresses inside the tunnel. These studies provided a conceptual framework for interpreting and predicting the displacements, stresses, and stability around the tunnel face.

The objective of this study is to demonstrate some aspects of the three-dimensional (3D) behaviour of large openings in weak rock subjected to high horizontal stresses. A detailed 3D finite element study, which explores the progressive development and evolution of induced near-field stresses and displacements during the advancement of a tunnel face, is conducted. The analyses concentrate on the relationships between rock mass strength and circumferential stresses, deformations, and plastic zone development at and near the advancing face in weak rock subjected to high in situ horizontal stresses. The significance of these effects will be sub- 
sequently discussed with respect to induced damage and rock mass instability during and after the tunnel construction.

\section{Rock mass parameters}

The tunnel investigated is approximately $13.8 \mathrm{~m}$ diameter and $10 \mathrm{~km}$ long constructed in geological and geometrical conditions corresponding to the proposed Sir Adam Beck Niagara Generating Station Number 3 (SABNG No. 3) project in Niagara Falls, Ontario (Yuen et al. 1992). The tunnel will be constructed in Queenston Shale at a depth of about $200 \mathrm{~m}$ from ground surface to the tunnel centreline.

Rock formations in this region are characterized by high initial horizontal stresses. Based on hydraulic fracturing tests at a depth of $200 \mathrm{~m}$, the in situ stresses involve maximum and minimum horizontal stresses $\left(\sigma_{\mathrm{h}}\right)$ of 24 and $18 \mathrm{MPa}$, respectively (with an average effective horizontal stress of $21 \mathrm{MPa}$ ), a vertical effective in situ stress of $5.2 \mathrm{MPa}$, and hence an initial stress ratio $K_{\mathrm{o}}=4$. The rock parameters used in the analysis are shown in Table 1 . The uniaxial compressive strength of the rock mass, $\sigma_{\mathrm{cm}}$, is related to the MohrCoulomb parameters by the relationship

$$
\sigma_{\mathrm{cm}}=\frac{2 c \cos \phi}{1-\sin \phi}
$$

where $c$ is the effective cohesion, and $\phi$ is the angle of internal friction.

\section{Method of analysis}

\subsection{Three-dimensional (3D) analysis}

The analyses were performed using a 3D elastoplastic finite element computer program using 20-noded brick elements with full (27 points) integration. The element performance was checked against closed-form solutions (AbdelMeguid 2002).

\subsection{Material nonlinearity}

The onset of plastic failure of the rock mass is defined by the Mohr-Coulomb criterion. In 3D principal stress space the failure surface associated with the Mohr-Coulomb criterion is an irregular hexagon pyramid with its axis coinciding with the hydrostatic axis as shown in Fig. 1. The presence of corners at lode angle $\theta= \pm 30^{\circ}$ creates a noncontinuous and nondifferentiable failure surface. In the present study, the smoothing algorithm suggested by Smith and Griffiths (1998) is adopted, whereby a smooth surface is substituted in the corners when (see Fig. 1)

$$
\left|\sin ^{-1} \theta\right|>0.492424 \quad\left(\theta=29.5^{\circ}\right)
$$

In this region, the surfaces are evaluated explicitly with either $\theta=30^{\circ}$ or $\theta=-30^{\circ}$, giving a circular surface over a small arc.

\subsection{Multiple excavation sequences}

Material was removed in several stages, so for the nonlinear analyses the final stress data are appropriate to the sequence of excavation that would be performed. This process must be conducted in such a way that equilibrium is main-
Table 1. Rock mass parameters (Hefny and Lo 1999).

\begin{tabular}{ll}
\hline Young's modulus, $E(\mathrm{MPa})$ & 15800 \\
Poisson's ratio, $v$ & 0.3 \\
Uniaxial compressive strength $(\mathrm{MPa})$ & \\
$\quad$ Intact rock, $\sigma_{\mathrm{ci}}$ & 37 \\
$\quad$ Rock mass, $\sigma_{\mathrm{cm}}$ & $5-37$ \\
Tensile strength, $\sigma_{\mathrm{t}}(\mathrm{MPa})$ & 4.2 \\
Cohesion, $c^{\prime}(\mathrm{MPa})$ & $1.2-9.0$ \\
Friction angle, $\phi^{\prime}\left({ }^{\circ}\right)$ & 38 \\
Dilation angle, $\psi^{\prime}\left({ }^{\circ}\right)$ & 0 \\
Average horizontal stress $(\mathrm{MPa})$ & 21 \\
Initial stress ratio, $K_{\mathrm{o}}$ & 4 \\
Unit weight, $\gamma\left(\mathrm{kN} / \mathrm{m}^{3}\right)$ & 26 \\
\hline
\end{tabular}

tained in the rock elements around the tunnel. Element removal was carried out using the procedure described by Brown and Booker (1985). Initially, the ground was stressed by its own weight. For each excavation stage, the geometry is modified and a new stiffness matrix and load vector are formed. The loads are removed in increments and the nonlinear equations were solved using a modified NewtonRaphson technique.

\section{Analysis details}

A parametric study was conducted (Abdel-Meguid et al. 2002) to check that the finite element mesh arrangement and boundary locations were adequate. The lateral boundaries of the mesh were located such that they would not significantly influence the predicted displacement of the tunnel lining. To meet this criterion it was necessary to locate the boundaries $88 \mathrm{~m}(7 D$, where $D$ is the tunnel diameter) from the tunnel centreline in the $x$ and $z$ directions. Behind the tunnel face, a distance of $70 \mathrm{~m}$ was necessary to ensure that plane strain conditions were reached based on the observed stress and displacement patterns.

The 3D finite element analysis was performed using 1210 20-noded isoparametric elements with a total of 6033 nodes arranged as shown in Fig. 2. The effect of mesh refinement on the calculated results was examined by comparing the calculated maximum displacement using a more refined mesh (5920 elements and 26965 nodes). The calculated displacement using fine mesh was slightly higher (by about $8 \%$ ) than that calculated using a coarser mesh; however, the calculation time required for the analysis was almost three times higher. Therefore, the first mesh is used in the parametric study presented herein. Nodes along the vertical boundaries may translate freely along the boundaries but are fixed against displacements normal to these boundaries. The nodes at the base are fixed against displacements in all directions.

In describing the results of 3D analysis, two stability criteria are presented as suggested by Lo et al. (1992); the first is the displacement around the tunnel opening which may be considered to indicate ground instability if excessive displacement developed. The second stability criterion is related to the development of plastic zones around the advancing face. For stable tunnels, plastic zones only develop at the 
Fig. 1. Mohr-Coulomb failure criterion. (a) Mohr-Coulomb surface. (b) Some smooth approximations in the $\pi$ plane.
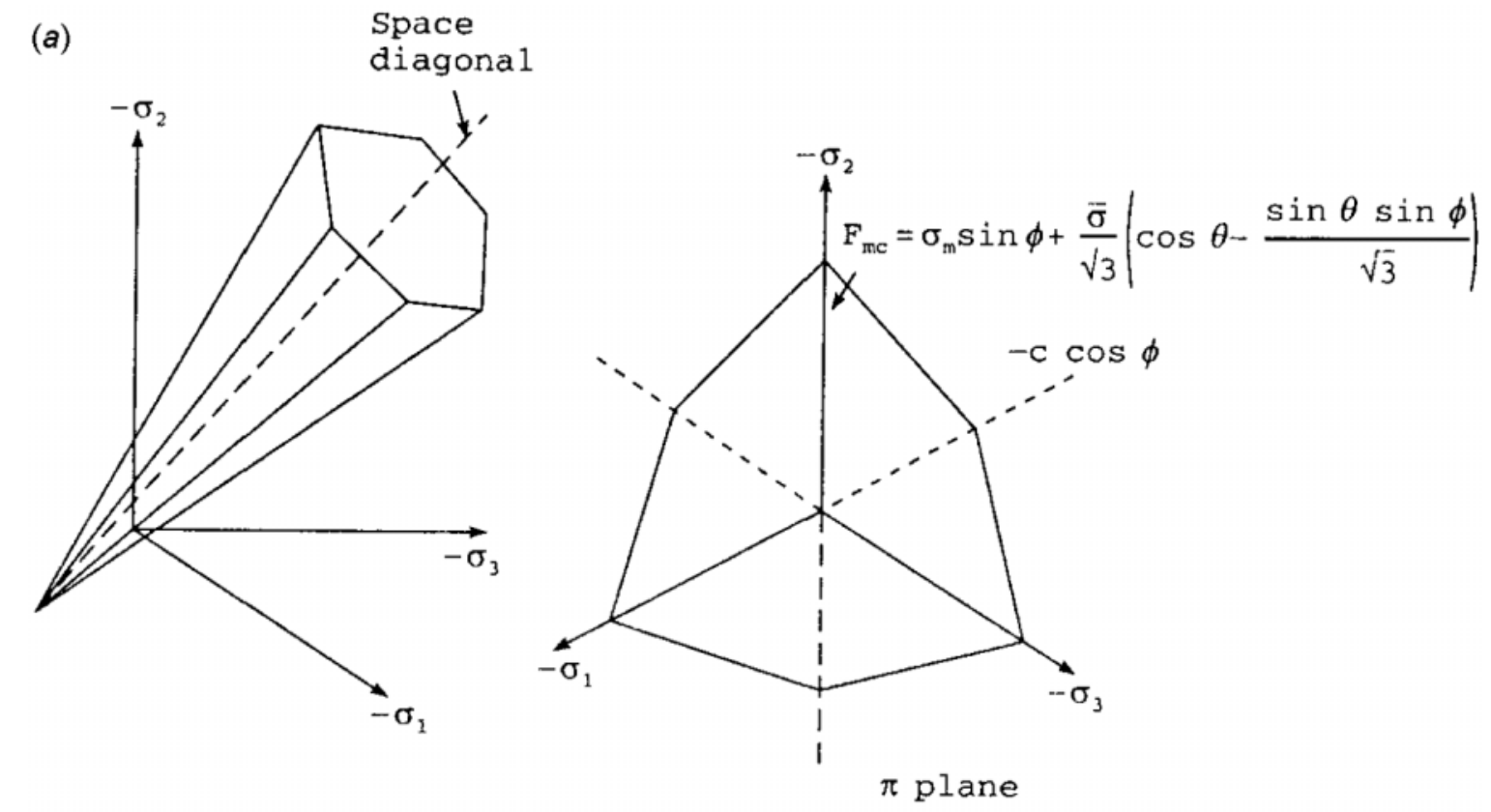

(b)

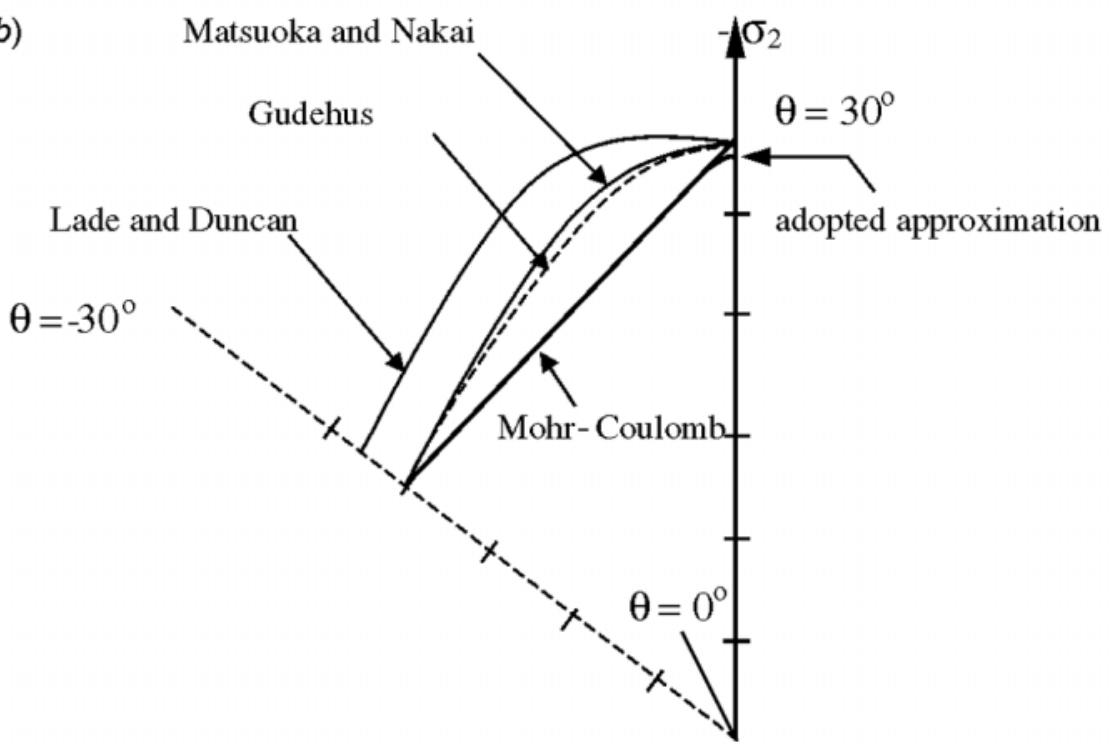

face corners, whereas for unstable ground a continuous plastic zone is formed at and in front of the tunnel face.

To investigate the effects of the rock mass strength on tunnel stability and deformation, the strength was reduced gradually by reducing the cohesion $\left(c^{\prime}\right)$. Five cases were examined representing a range of rock mass quality from good to poor using $c^{\prime}=9.0,4.5,3.5,2.5$, and $1.2 \mathrm{MPa}$. These values correspond to a ratio of rock mass strength to in situ stress $\left(\sigma_{\mathrm{cm}} / p_{\mathrm{o}}\right)$ of about 3.0,1.4, 1.0, 0.8, and 0.4, respectively; $p_{\mathrm{o}}=\left(\sigma_{\mathrm{v}}+\sigma_{\mathrm{h}}\right)$, where $\sigma_{\mathrm{v}}$ and $\sigma_{\mathrm{h}}$ are the vertical and horizontal stresses, respectively.

\section{Effect of construction simulation on the predicted tunnel behaviour}

One of the most common methods of simulating the advancing tunnel is a step-by-step incremental excavation scheme. Elements in the region to be excavated are initially active, and at a designated step these elements are deactivated. If a tunnel is instantaneously excavated from an infinite distance to the section of interest shown in Fig. 3 ("one-stage" excavation), it is implicitly assumed that, up to this section, the cumulative nonlinear $3 \mathrm{D}$ effects due to the 
Fig. 2. Finite element mesh used in the $3 D$ analysis.

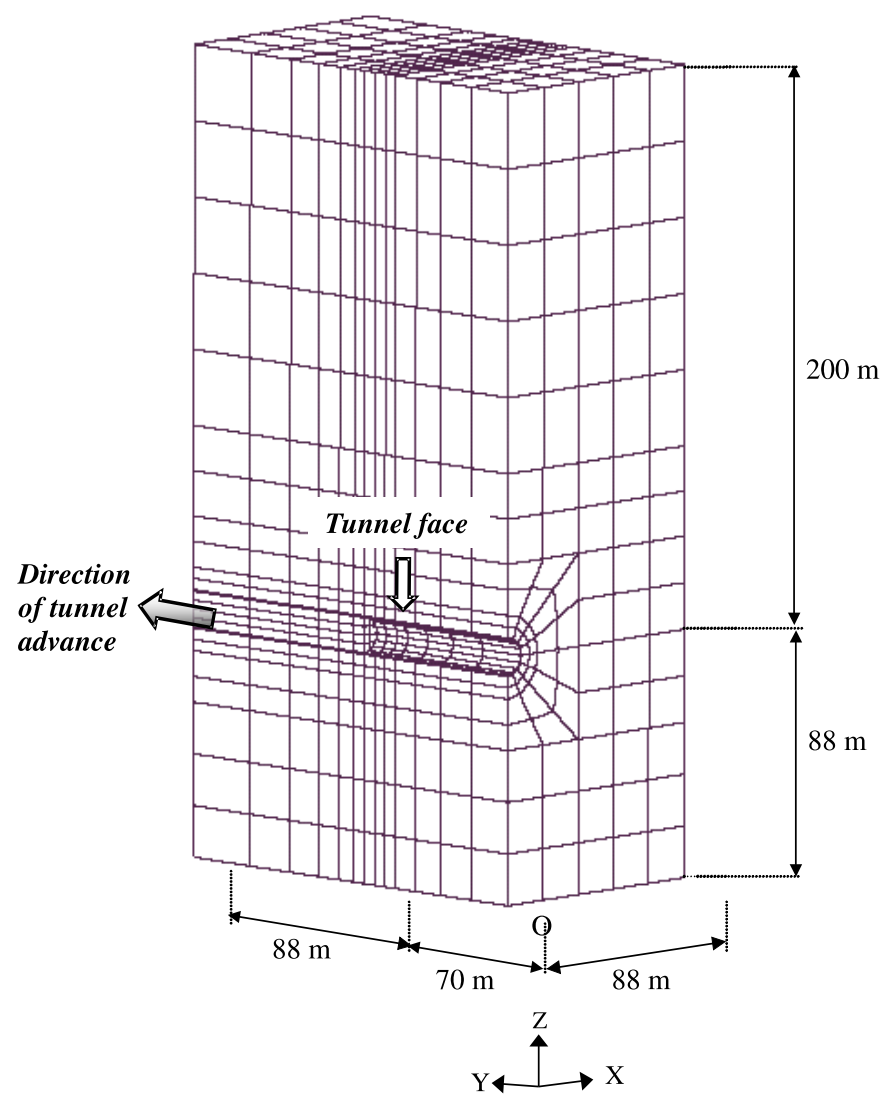

advancing tunnel face are ignored and the ground deformation behind the tunnel is primarily due to the release of radial stress around the tunnel opening. The complete $3 \mathrm{D}$ response of the ground is only allowed to develop when the tunnel heading is directly below this section.

For closed-face mechanical tunnelling, the step size to be deactivated at each stage of excavation should be equivalent to the actual distance pushed ahead by the hydraulic jacks against previously erected lining (typically about $0.75 \mathrm{~m}$ ). For the current problem of interest, the advance rate is more continuous (open-face tunnelling) and a gradual 3D ground deformation ahead of the tunnel face is developed. The logical approach to simulate the tunnel advance in these cases would be to use a sequence of very small steps to simulate the excavation. The associated computational cost in this case would be impractically large, and an alternative approach was adopted as discussed in the following.

Lee (1989) showed that for tunnelling in soft soils, the change of radial stress (normal to the tunnel axis) with an increase in the distance ahead of the tunnel face is very small, which indicated that the size of the excavation step adopted in the step-by-step incremental technique has a very limited effect on the resulting radial behaviour of the tunnel. On the other hand, the axial stress profile (in the direction of tunnel axis) ahead of the face is very nonlinear, increasing to a maximum value at about $0.8 \mathrm{D}$ and then decreasing to zero at a distance about $1.5 \mathrm{D}$ ahead of the face. The results suggested that a step size of greater than $1.5 D$ would predict a ground response essentially similar to that of a single-step excavation simulation, since the stress release at and around the heading is virtually the initial stress of the ground.

To study the effect of step size on 3D behaviour of tunnels in weak rock (Table 1), the case of a tunnel constructed in rock with strength $\sigma_{\mathrm{cm}} / p_{\mathrm{o}}$ between 0.4 and 3.0 was examined using three different simulation schemes: (1) single-step excavation wherein the elements up to section 1-1 are instantaneously deactivated (Fig. 3); (2) excavation of the tunnel in four equal stages with a step size of approximately $15-20 \mathrm{~m}$ $(1.2 D-1.5 D)$; and (3) excavation of the tunnel up to a distance of $15 \mathrm{~m}$ from the face followed by three stages with equal step size of $5 \mathrm{~m}(0.4 D)$. The results are summarized in Fig. 3 for the inward displacements at the tunnel crown, springline, and face centre and indicate that, for rock mass strength greater than the in situ stress $\sigma_{\mathrm{cm}} / p_{\mathrm{o}} \geq 1.0$, there was no significant difference in displacement obtained for the different excavation schemes. Displacements are represented in dimensionless form

$$
\Omega=u E / a p_{\mathrm{o}}
$$

where $u$ is the displacement, $E$ is Young's modulus, and $a$ is the tunnel radius. For $\sigma_{\mathrm{cm}} / p_{\mathrm{o}} \leq 1$, excavation scheme 2 predicted displacements up to $8-10 \%$ higher at the crown and springline than that predicted by the single-step scheme. At the tunnel face, the difference was about $8 \%$ using excavation scheme 3 with three small stages close to the face. The plane strain cross section was reached at approximately the same distance from the face using the three excavation schemes. It was also found that different excavation schemes provided similar behaviour for the crown and springline but that scheme 2, four equal stages, provided displacements that are generally higher than those obtained using other schemes. At the tunnel face, however, scheme 3 provided higher displacement at the face and may be considered the most conservative scheme regarding the displacement at the tunnel face if the face response is of prime interest.

Based on these observations, it is concluded that a singlestep excavation scheme provides a simple and economical way of analyzing and understanding the behaviour of tunnels in weak rock. For poor quality rock masses, this technique may underestimate the tunnel response by about $10 \%$ as compared with using four excavation stages. This level of approximation may be acceptable in many practical applications and is, therefore, adopted in the present study. These results also show, however, that more detailed simulation would be required when stability conditions are critical.

\section{Tunnel deformation}

Displacement vectors surrounding the tunnel face are shown in Fig. 4 for the cases of good quality $\left(\sigma_{\mathrm{cm}} / p_{\mathrm{o}}=3.0\right)$ and poor quality $\left(\sigma_{\mathrm{cm}} / p_{\mathrm{o}}=0.4\right)$ rock masses. For the first case, $\sigma_{\mathrm{cm}} / p_{\mathrm{o}}=3.0$, no plasticity developed around the tunnel and the response was elastic. The deformation pattern is dominated by high inward horizontal displacement at the tunnel face and springline. Small outward displacements were calculated at the crown and invert. The directions and relative magnitudes of these displacements are consistent with those predicted and observed in case histories in southern Ontario (for example, Lo et al. 1984; Lo 1989). 
Fig. 3. Effect of construction simulation on predicted results. See Table 1 for rock properties.
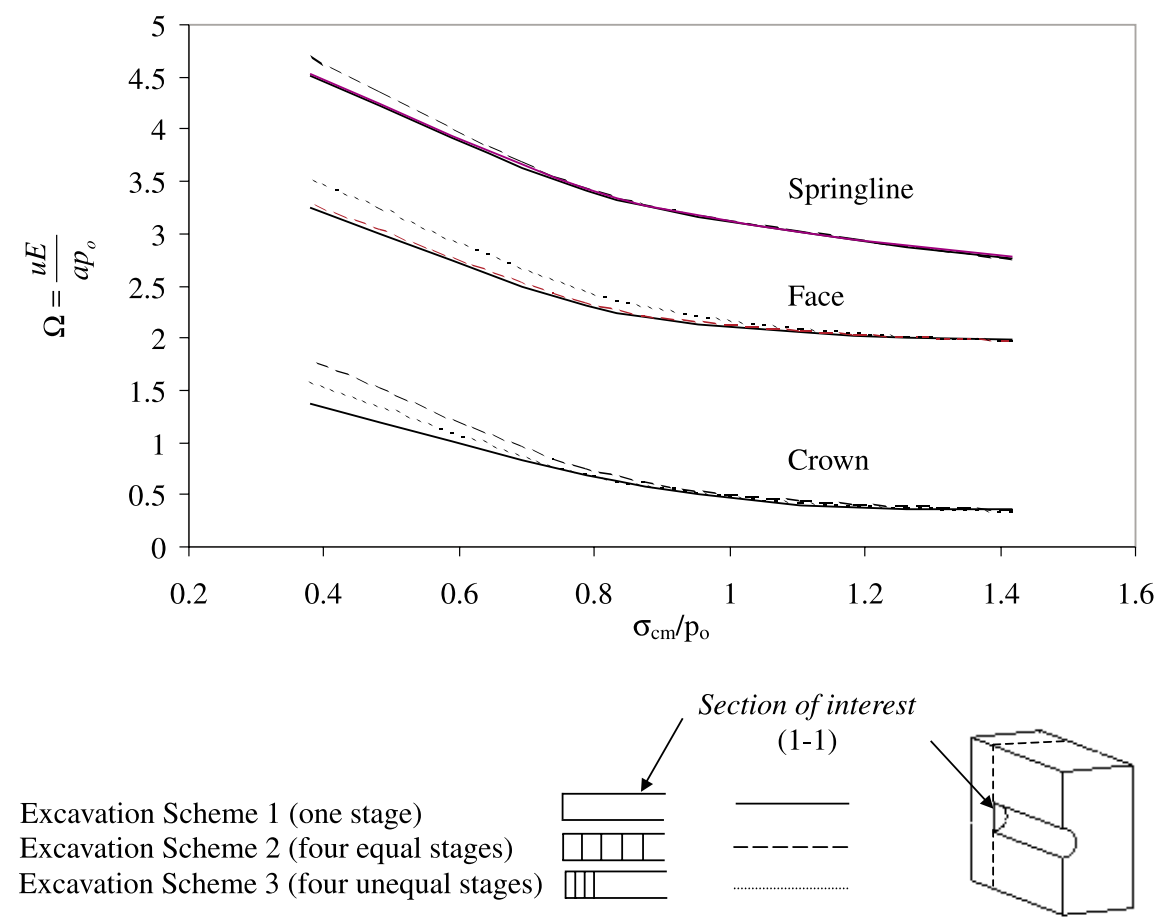

For the cases where $\sigma_{\mathrm{cm}} / p_{\mathrm{o}}$ ranged from 1.8 to 0.4 , the radial displacements in excess of $1 \mathrm{~mm}$ in the $x$ direction (normal to the tunnel axis) started at a distance of about four times the tunnel diameter from the tunnel circumference and reached its maximum at the tunnel springline. In the $y$ direction, the direction of tunnel advance, displacement started at a distance of about twice the tunnel diameter ahead of the advancing face and reached its maximum at the centre of the tunnel face. For a low-strength rock mass $\left(\sigma_{\mathrm{cm}} / p_{\mathrm{o}}=0.4\right)$, inward radial displacements were calculated at the tunnel springline, crown, and invert. An outward movement pattern was observed near the crown and invert close to the tunnel opening, however (see Fig. 4b).

Figure 5 shows the vertical displacement profiles near the tunnel crown for different rock mass strengths. The displacement in excess of $1 \mathrm{~mm}$ in the $z$ direction started at a distance of about four times the tunnel diameter from the tunnel circumference and changed from an outward to inward direction at a distance $z / a$ of less than 2 for the examined range of rock mass strengths. At the crown line, the inward displacement increased as the rock mass strength decreased. This behaviour may be explained by the elastic response of the rock mass away from the developed plastic zone under the high in situ horizontal stresses in the rock prior to the tunnel excavation. This observation has significant implications for the interpretation of multiple-point extensometer results in field measurements. Different displacement magnitudes and directions may be measured depending on the location of the measuring points with respect to the tunnel circumference.

As an illustration, the deformed shape of the tunnel opening for weak rock $\left(\sigma_{\mathrm{cm}} / p_{\mathrm{o}}=1.0\right)$ is shown in Fig. 6 represented by the noncontinuous line along with the definitions of the parameters examined. The effect of high horizontal stresses is manifested in the form of a large displacement at the tunnel springline $\left(u_{\mathrm{sl}}\right)$ as compared with that of the crown $\left(u_{\mathrm{c}}\right)$ accompanied by a considerable inward displacement at the centre of the tunnel face $\left(u_{\mathrm{fm}}\right)$. The effect of these deformations on stability conditions in the tunnel will be discussed in the following sections.

Figure 7 shows the relationship between dimensionless displacements for different rock mass strengths. For a rock mass strength greater than twice the in situ stresses, elastic behaviour was observed and displacements at the springline and face centre were 15 and $11 \mathrm{~mm}$, respectively, for parameters given in Table 1. Displacements increased as the rock mass strength decreased and reached the highest value when the strength was less than one half the in situ stresses. Plane strain conditions were reached at a distance $y$ of about one tunnel diameter from the tunnel face for the range of strengths studied.

\subsection{Displacements ahead of an advancing tunnel face}

To understand the displacements generated by an advancing face during the tunnel construction, radial displacements at the tunnel crown and springline are plotted in Figs. 8 and 9 , respectively. Displacements at the face centre ahead of the advancing face are shown in Fig. 10. The face advance is represented by $y / a$, where $y$ is the distance from the face to the point under consideration, and $a$ is the radius of the tunnel.

The variation of radial displacements at the tunnel crown with distance from the advancing face is shown in Fig. 8. It was found that displacement changes begin to occur at a distance of about two to three radii $(y / a=-2$ to -3$)$ from the tunnel face. This may be attributed to the stress release in the longitudinal direction of the tunnel. For $y / a=0$ (at the tunnel face), upward movement of the crown was observed 
Fig. 4. Displacement vectors around unlined tunnel: $(a)$ good quality rock mass $\left(\sigma_{\mathrm{cm}} / p_{\mathrm{o}}=3.0\right) ;(b)$ poor quality rock mass $\left(\sigma_{\mathrm{cm}} / p_{\mathrm{o}}=\right.$ $0.4)$.
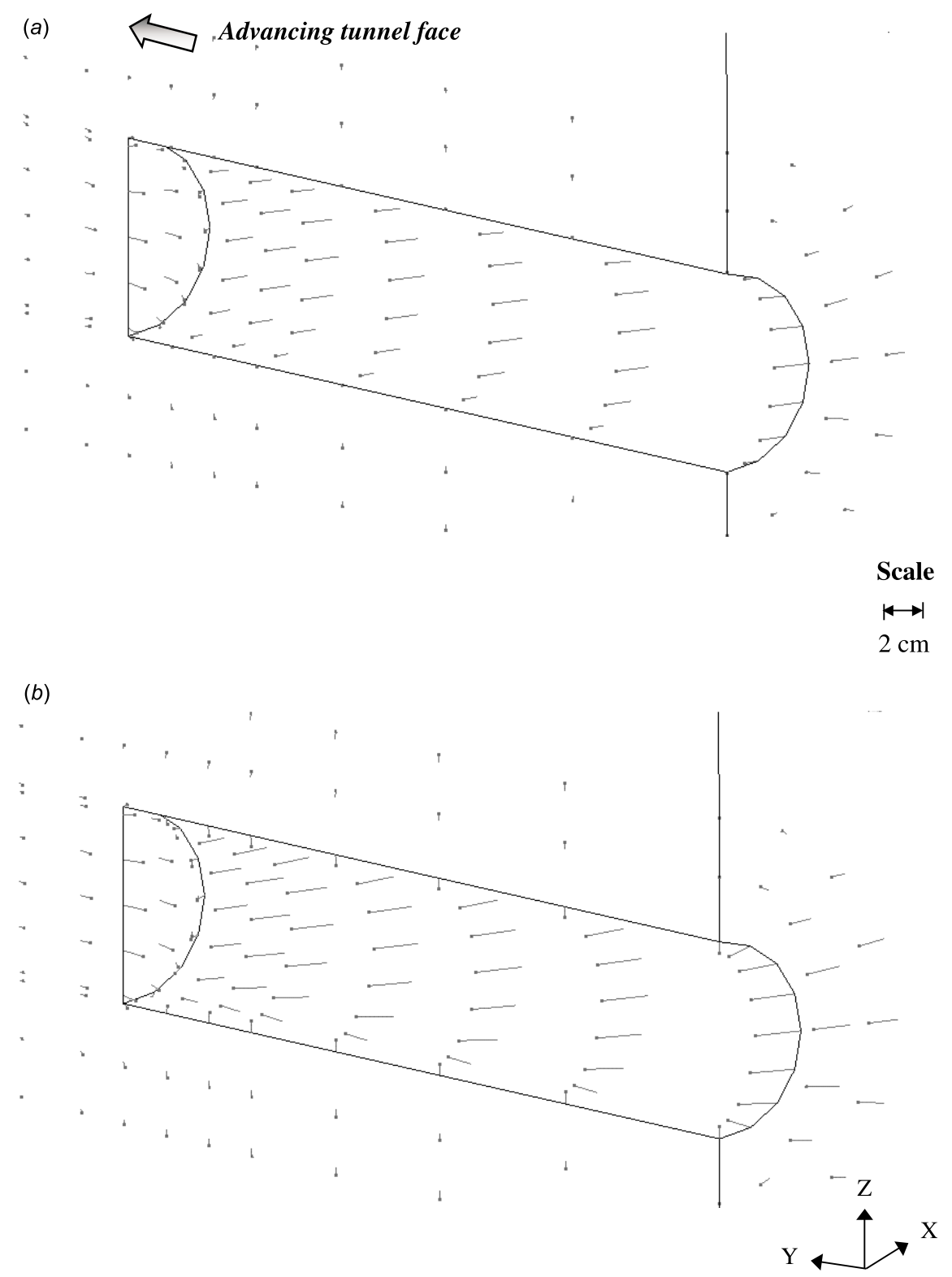

for the considered range of rock mass strengths. The change in radial displacement at the tunnel crown was large for poor quality rock $\left(\sigma_{\mathrm{cm}} / p_{\mathrm{o}}=0.4\right)$ and small for good quality rock $\left(\sigma_{\mathrm{cm}} / p_{\mathrm{o}}=3.0\right)$

Figure 9 shows the variation of radial displacement at the tunnel springline. The rate of displacement change occurred for all values of $\sigma_{\mathrm{cm}} / p_{\mathrm{o}}$ when the tunnel passes the section. The ratio of displacement at the face to that at the plane strain varies from 0.3 to 0.5 as the rock strength decreased from 3.0 to 0.4 .

For both the tunnel crown and the springline, displacement changes are essentially completed when the tunnel face advances to a distance of two to three radii beyond the face $(y / a=2$ to 3$)$, i.e., when the plane strain conditions are reached. At the face centre, displacement in excess of $1 \mathrm{~mm}$ started to develop at a distance $y / a=-4$ ahead of the advanc- ing face and rapidly increased at a distance $y / a=-1$ to reach its maximum value at the face centre as shown in Fig. 10.

The calculated displacement pattern and magnitude for the case of rock mass strength to in situ stress $\left(\sigma_{\mathrm{cm}} / p_{\mathrm{o}}=3.0\right)$ are consistent with those predicted by Lo et al. (1984) for similar in situ stress conditions $\left(K_{\mathrm{o}}=4\right)$ based on analysis of a tunnel in elastic rock. The practical significance of these results is summarized in the following paragraph.

For tunnelling in soft ground, displacement and stress measurements are usually performed by installing the measuring devices well ahead of the advancing face so that complete changes of stress and displacement can be recorded. For tunnelling in rock, however, tunnel displacement is usually measured in practice using convergence points and extensometers installed near the face from inside the tunnel. A comparison is usually made between the theoretically calcu- 
Fig. 5. Vertical-displacement profile near the tunnel crown at a plane strain cross section.

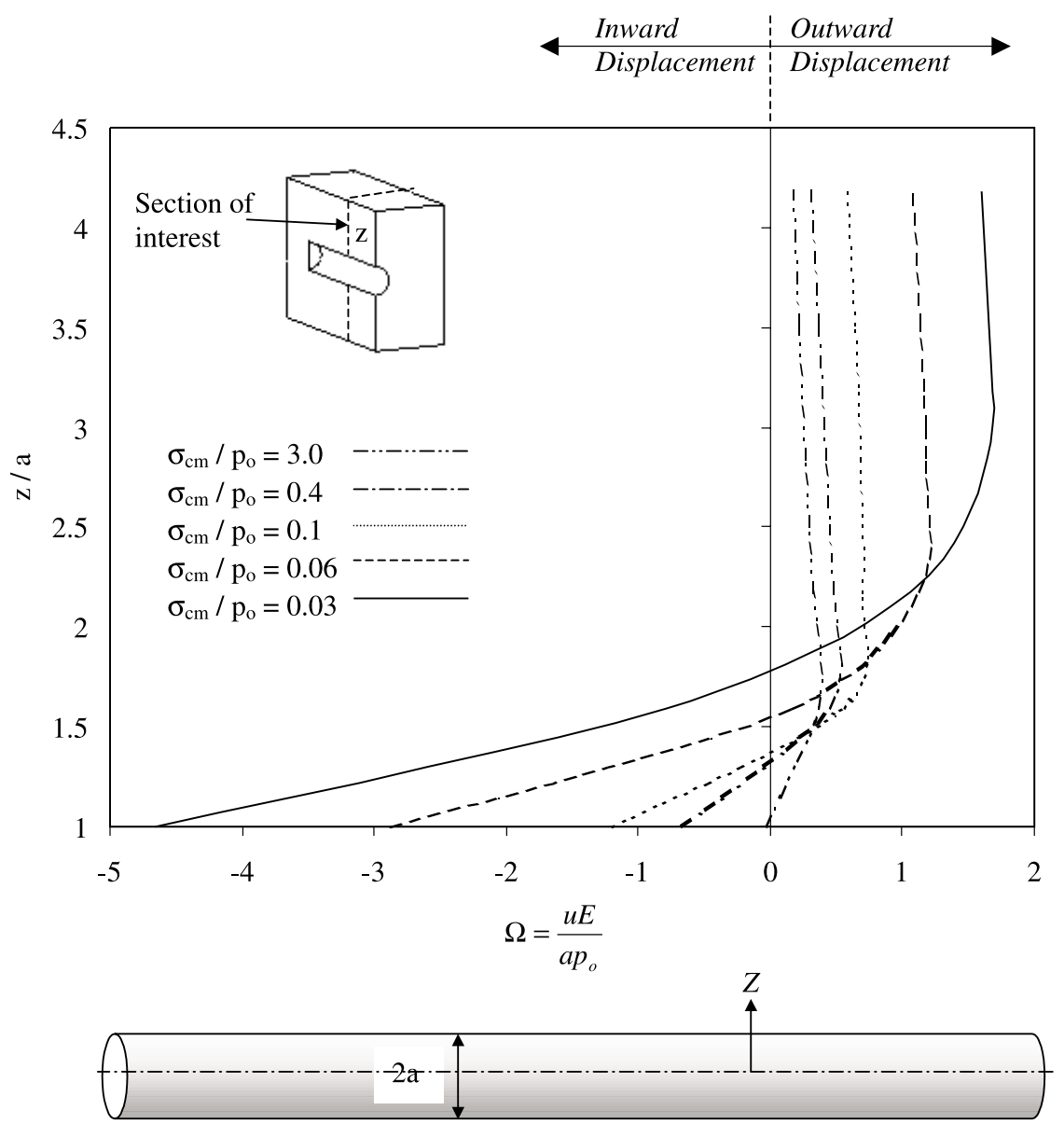

Fig. 6. Deformed shape of the tunnel for the case of $\sigma_{\mathrm{cm}} / p_{\mathrm{o}}=1.0$ (relative to original geometry). $u_{\mathrm{c}}$, radial displacement at the crown (plane strain conditions); $u_{\mathrm{fm}}$, axial displacement at the face centre; $u_{\mathrm{sl}}$, radial displacement at the springline (plane strain conditions).
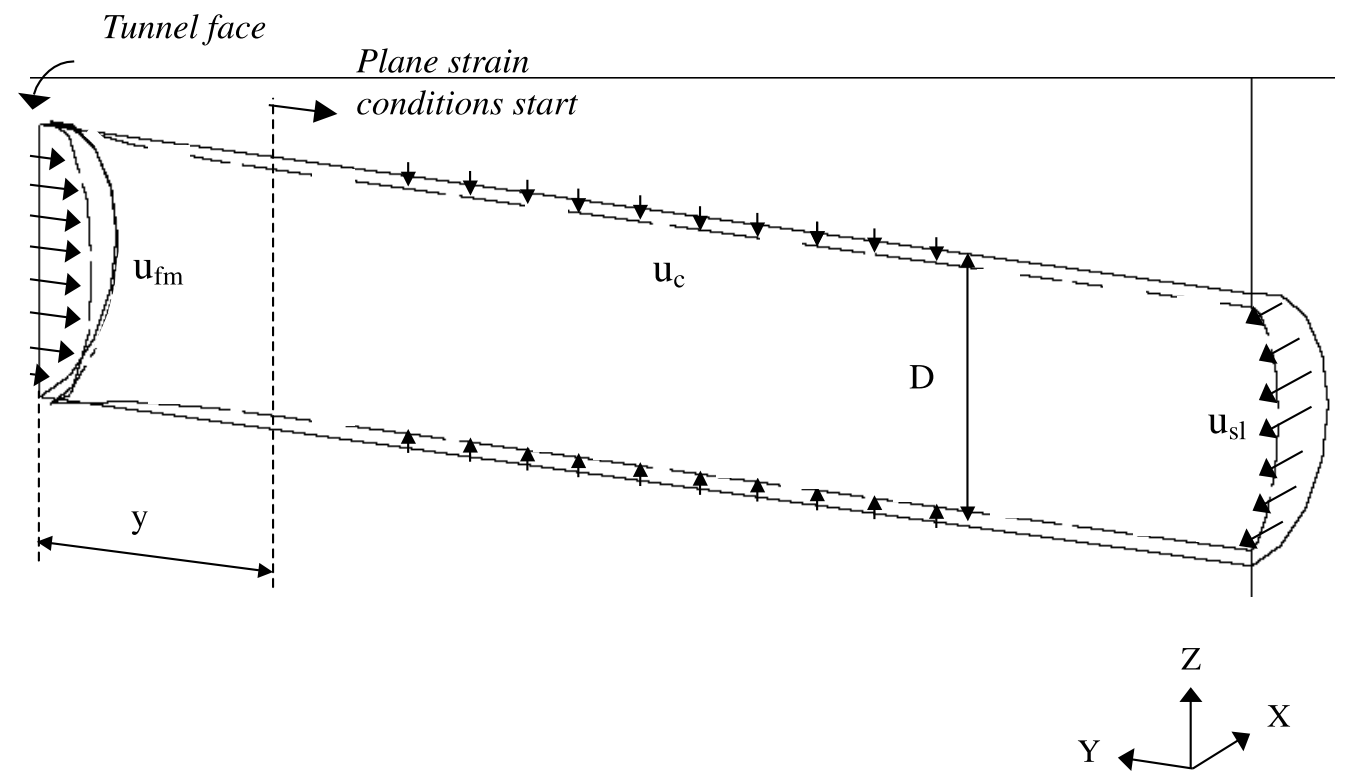
Fig. 7. Relationship between rock mass strength and tunnel displacement (see Table 1 for rock properties).

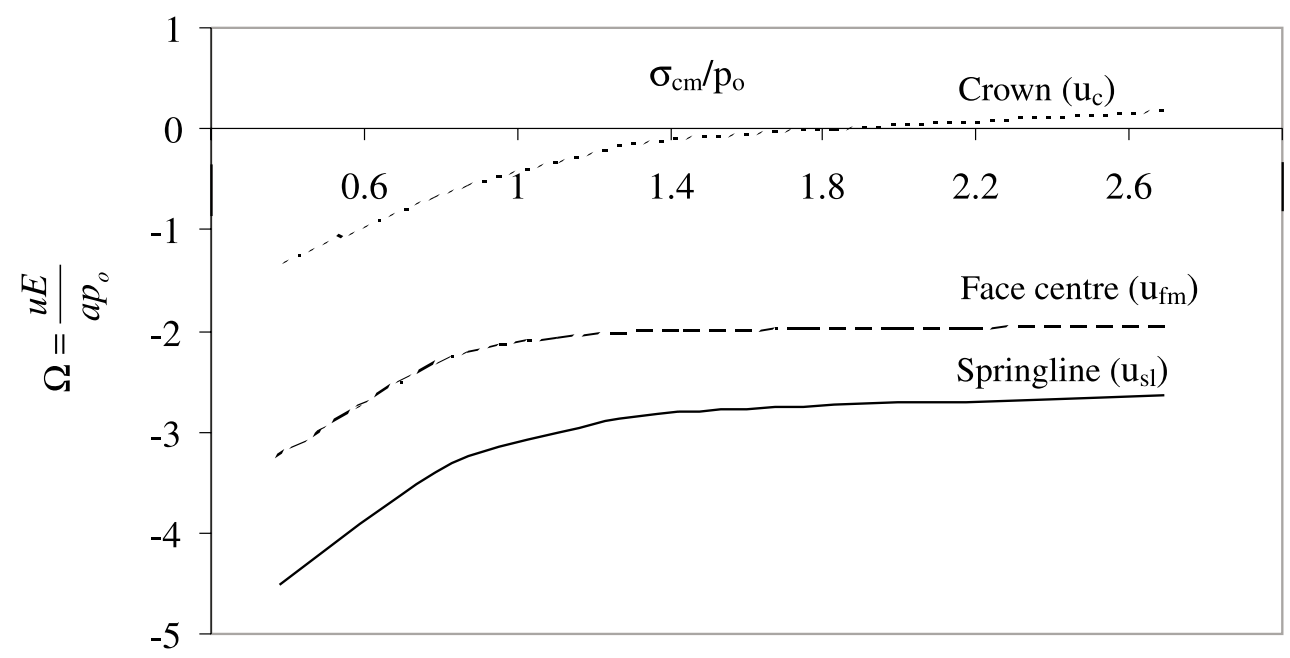

Fig. 8. Radial displacement at the tunnel crown with tunnel face advance.

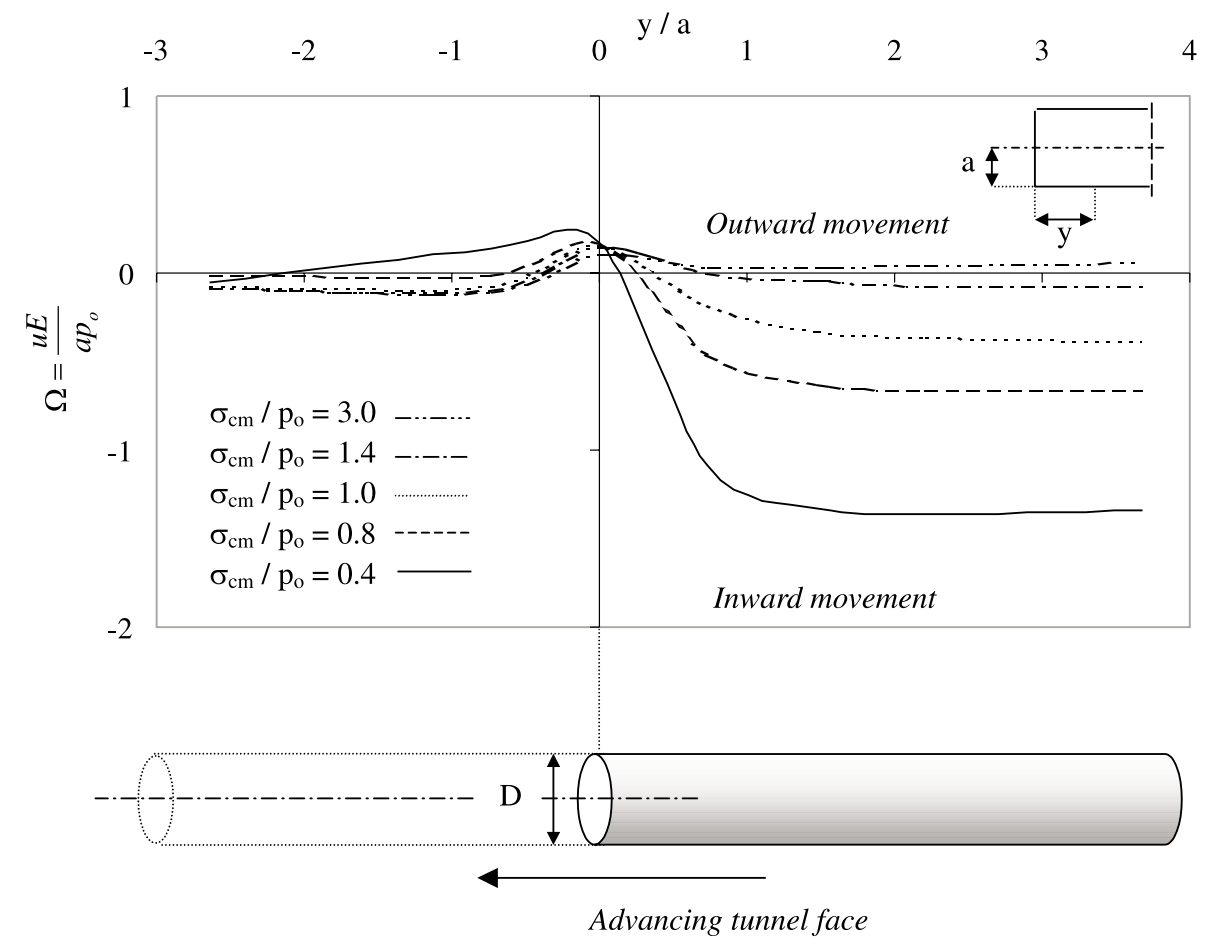

lated displacements using plane strain solutions and actual measurements. It is evident from Figs. 8 and 9 that much of the displacement at the tunnel springline and crown would have already occurred prior to the installation of instruments, depending on the ratio $y / a$ at which the instruments are located. For example, for $\sigma_{\mathrm{cm}} / p_{\mathrm{o}}=0.4$ about $50 \%$ of the springline convergence has occurred at the tunnel face and therefore the measured convergence would represent only $50 \%$ of the actual developed deformation, even if instruments were installed at the tunnel face. At greater distances (for example, $y / a \geq 1$ ), the recordable displacement would be very small. Great care must be taken, therefore, in interpreting the results of field measurements, e.g., back-calculating mass modulus of the rock, and this observation must be taken into account when planning field instrumentation programs.

To demonstrate the effect of the rock mass strength on the changes in deformed shape of the tunnel close to the face and appreciate the displacement values, two cross sections at distances of $5 \mathrm{~m}(y / a=0.75)$ and $10 \mathrm{~m}(y / a=1.5)$ from the face are presented in Fig. 11. Displacements at the springline are greater than those at the crown and generally decreased with increasing rock mass strength. A slight increase in displacement was observed with increasing distance from the face as the section approaches plane strain conditions. These results confirm the previous observations of the radial 
Fig. 9. Radial displacement at the tunnel springline with tunnel face advance.

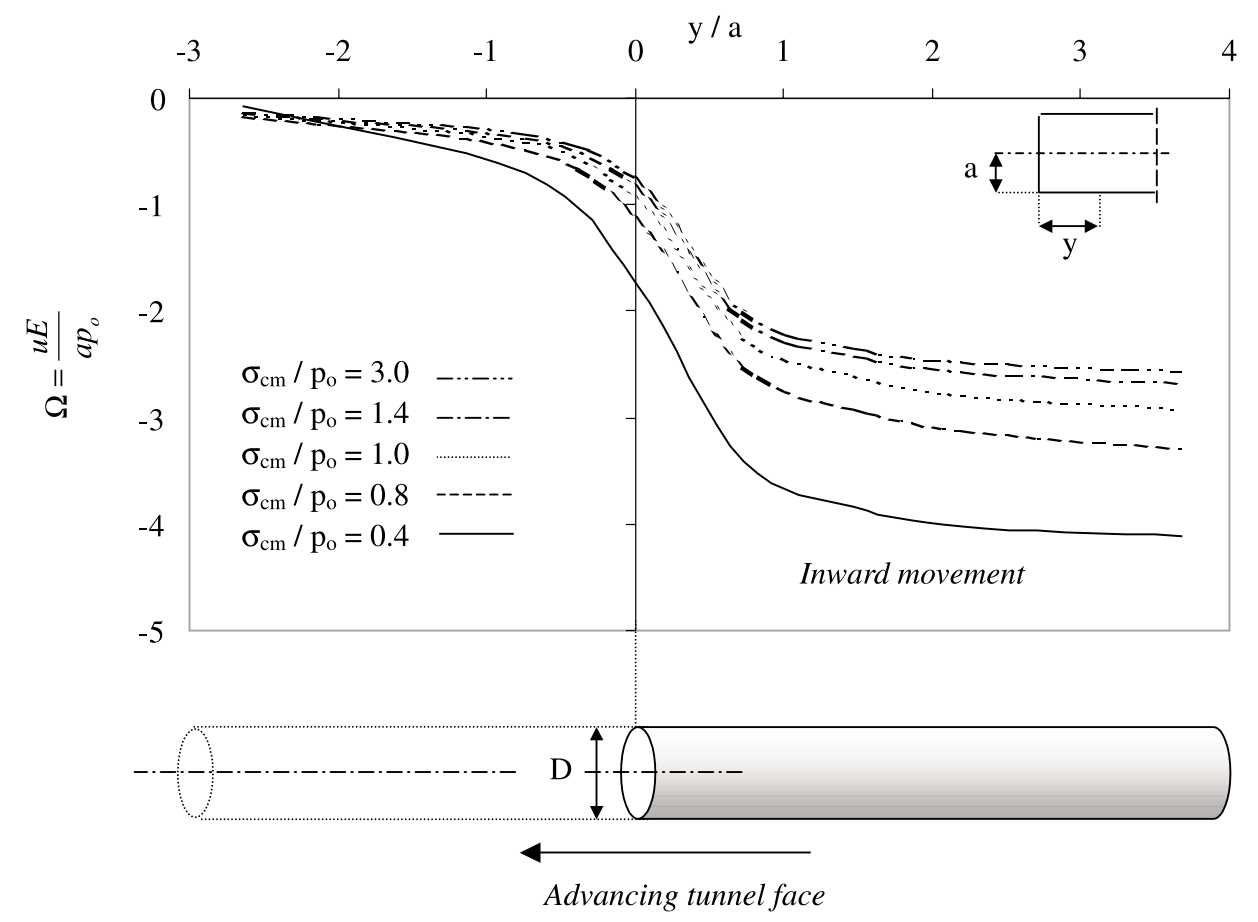

Fig. 10. Displacement at the face centre ahead of the advancing face.

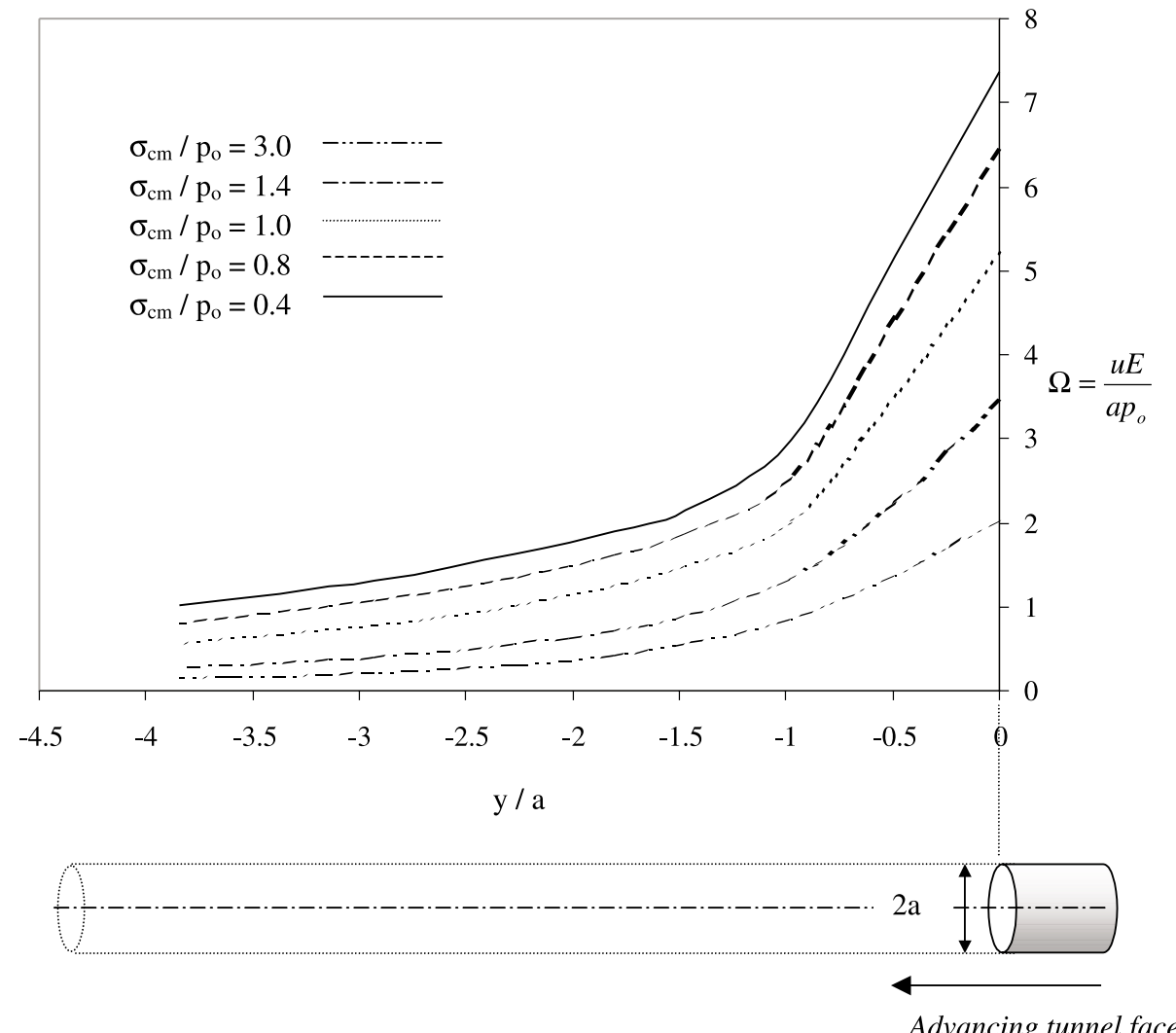

displacement changes as the tunnel advances, where the displacement change was rapid for a distance equal to the tunnel radius. For the analyzed tunnel $(13.8 \mathrm{~m}$ diameter) this means that no significant changes are expected beyond a dis- tance of about $7 \mathrm{~m}$ from the tunnel face. This is particularly true for the case of weak quality rock $\left(\sigma_{\mathrm{cm}} / p_{\mathrm{o}}=1.0\right)$, as discussed in the following section.

A different way of looking at the displacement results 
Fig. 11. Deformed shape of the tunnel for different distances from the face: (a) $y=5 \mathrm{~m}, y / a=0.75 ;(b) y=10 \mathrm{~m}, y / a=1.50$.
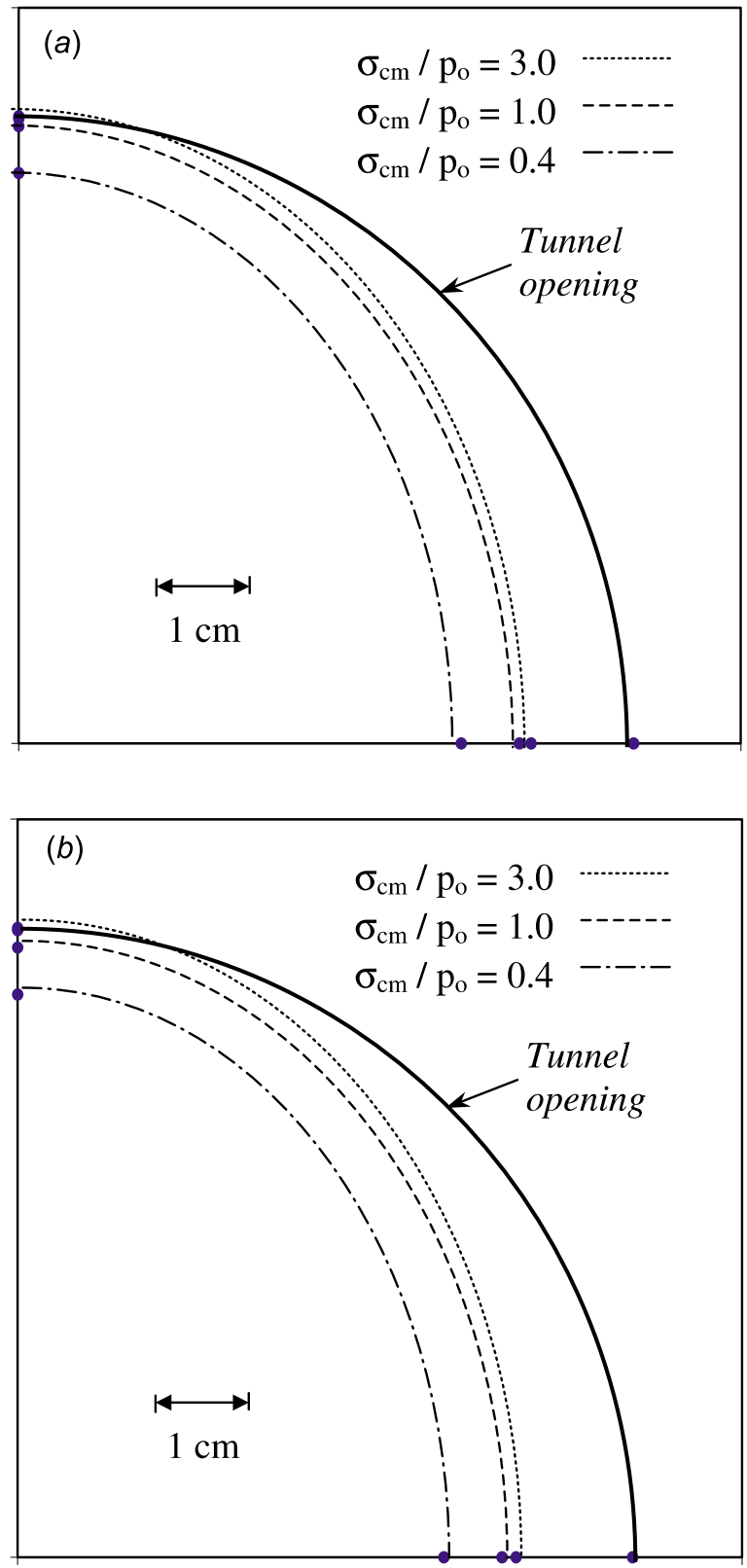

close to the face and the effect of face advance on the deformed shape of the tunnel are shown in Fig. 12. The results are presented for the cases of good and poor quality rock masses. For good quality rock (Fig. 12a), there was inward displacement at the tunnel springline but no significant displacement at the tunnel crown. These displacements increased with increasing distance from the tunnel face. For poor quality rock (Fig. 12b), inward displacement around the tunnel circumference was calculated. These displacements slightly decreased close to the tunnel face.

\section{Tangential stresses}

The advance of a tunnel face in a prestressed rock mass would result in the disturbance and redistribution of the pri-
Fig. 12. Effect of face advance on the deformed shape of the tunnel: $(a) \sigma_{\mathrm{cm}} / p_{\mathrm{o}}=3.0 ;(b) \sigma_{\mathrm{cm}} / p_{\mathrm{o}}=0.4$.
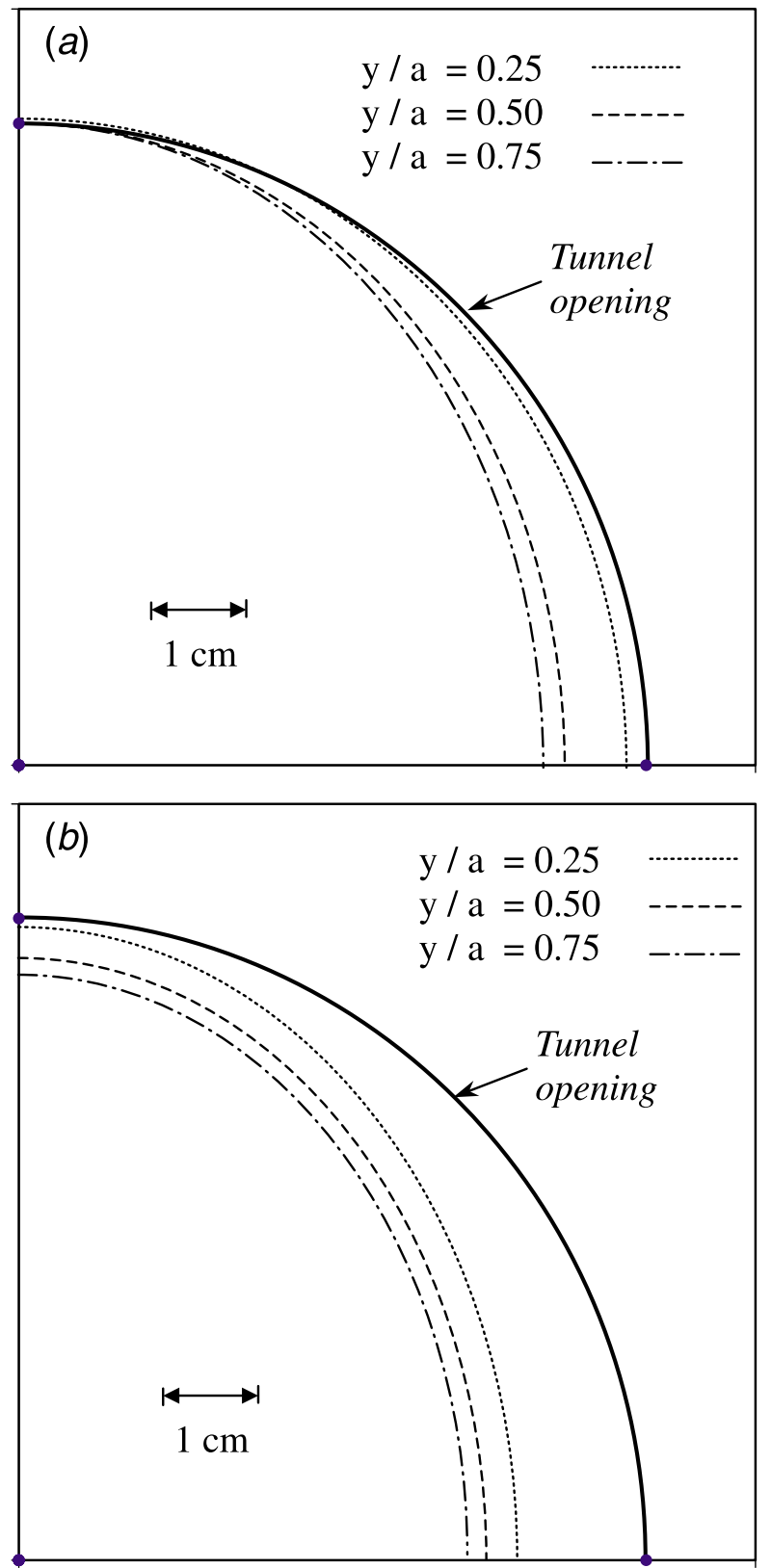

mary in situ stress field. This disturbance involves changes in both magnitude and orientation of stresses in the proximity of the tunnel boundary. In the context of this study, the tangential stresses refer to the direct stresses in the circumferential direction of the tunnel opening. The tangential stress distribution at a plane strain cross section and the changes in tangential stresses with distance from the tunnel face are presented in the following sections based on results of the 3D analyses.

\subsection{Tangential stresses at a plane strain cross section and the tunnel face}

The distribution of tangential stresses at a plane strain cross section across the tunnel is shown in Fig. 13. Compressive stresses were calculated at the tunnel crown and in- 
Fig. 13. Distribution of tangential stresses at a plane strain cross section of the tunnel: $(a) \sigma_{\mathrm{cm}} / p_{\mathrm{o}}=3.0(\mathrm{elastic}) ;(b) \sigma_{\mathrm{cm}} / p_{\mathrm{o}}=1.4$; (c) $\sigma_{\mathrm{cm}} / p_{\mathrm{o}}=1.0 ;(d) \sigma_{\mathrm{cm}} / p_{\mathrm{o}}=0.8 ;(e) \sigma_{\mathrm{cm}} / p_{\mathrm{o}}=0.4$. See Table 1 for rock mass properties.
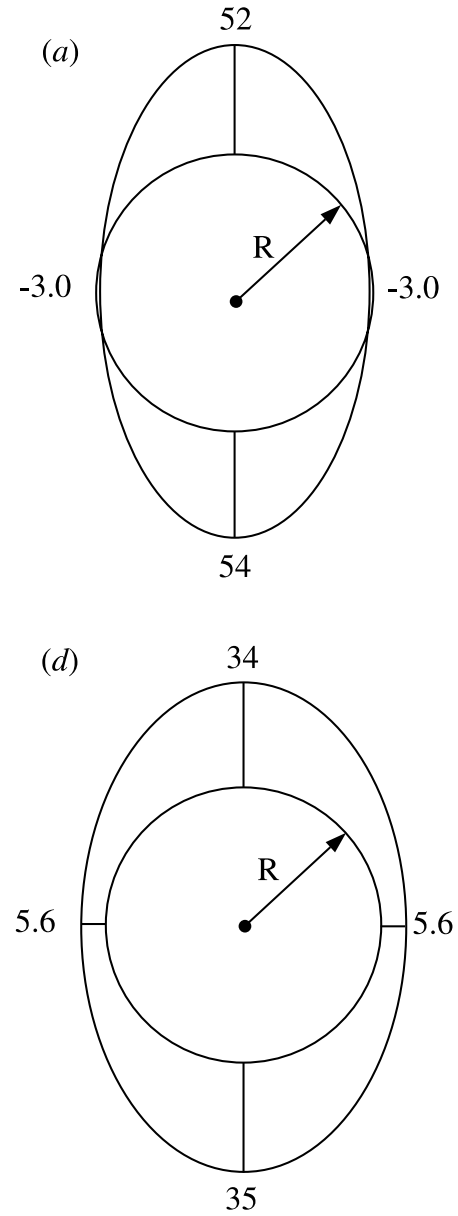
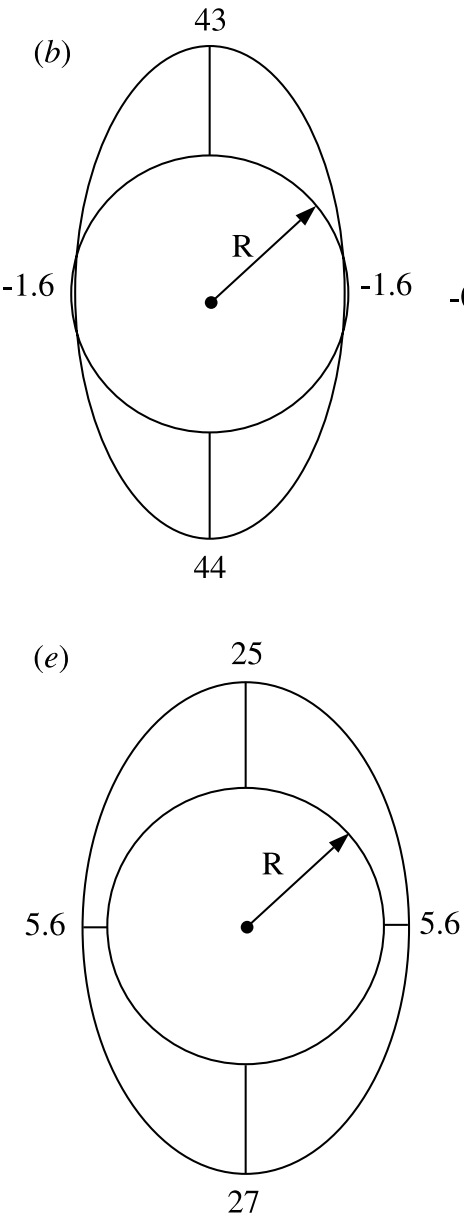
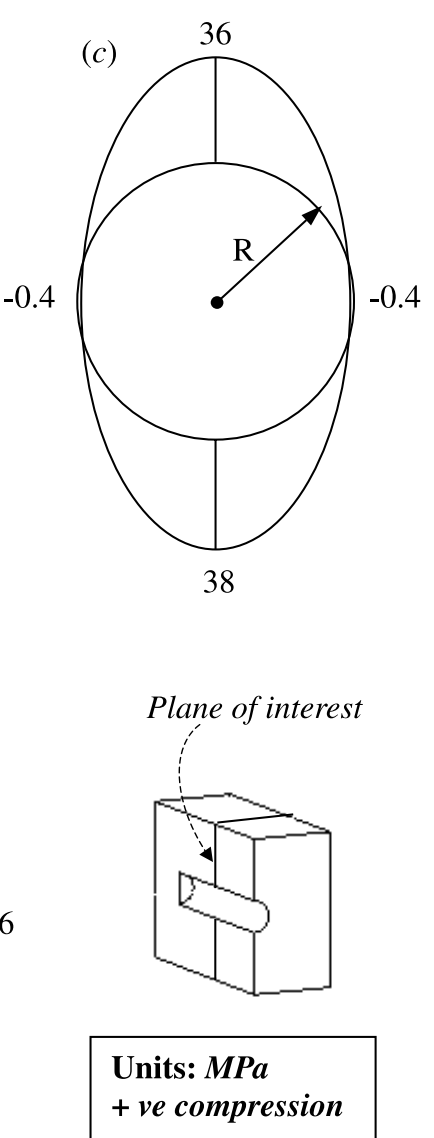

vert for the entire range of rock mass strengths examined. These stresses decreased from $52 \mathrm{MPa}$ for $\sigma_{\mathrm{cm}} / p_{\mathrm{o}}=3.0$ to about $25 \mathrm{MPa}$ for $\sigma_{\mathrm{cm}} / p_{\mathrm{o}}=0.4$. Tensile stresses were observed at the springline for the range $\sigma_{\mathrm{cm}} / p_{\mathrm{o}}=1.0-3.0$. As the strength decreased, compressive stresses started to develop and reached a value of about 5.6 $\mathrm{MPa}$ for $\sigma_{\mathrm{cm}} / p_{\mathrm{o}}=0.4$. The calculated tangential stresses for the elastic case were compared with those for the closed-form solution from which maximum stresses of about 58 and $-5 \mathrm{MPa}$ were found at the tunnel crown and springline, respectively. These values are slightly higher than the calculated values using the finite element analysis. This may be attributed to the fact that stresses are being calculated in the finite element analysis at the Gauss points, which are located at a distance of about $0.5 \mathrm{~m}$ from the tunnel perimeter for the elements surrounding the tunnel opening.

The significance of the previous results is that, under a given high in situ stress value, the rock mass strength has a great influence on the redistributed tangential stresses around the tunnel opening. A failure pattern in the form of cracking along the springline may develop due to the possible development of tensile stresses in the rock, for unlined tunnels in strong rock. It should be noted that high tensile stresses induced at the springline level have been measured by Lo et al. (1984) in strong rock $\left(\sigma_{\mathrm{cm}} / p_{\mathrm{o}}=17.0\right)$. The theo- retical results are, therefore, consistent with the field measurements.

To investigate the effect of the stress redistribution on the tunnel face and to examine the possible overstressing of the rock mass at the face, tangential and radial stresses along the crown-invert diameter were calculated and are shown in Figs. 14 and 15, respectively. Tangential stresses are compressive near the tunnel crown and invert for the range of rock mass strength examined as shown in Fig. 14. These stresses ranged between 2.5 and 3 times the average in situ stresses. In Fig. 15, tensile radial stresses were found for a high-strength rock mass, with a maximum value at the face centre as shown in Fig. 15a. These results are consistent with those reported by Lo et al. (1984). Under such conditions, tensile fracture occurs as the phenomenon of rock burst. Case histories reported by Martna (1970) indicated that severe rock-bursting conditions occurred in highstrength rock mass during the excavation of the Headrace tunnel in Sweden. Rock bursting was reported near the tunnel heading, following the face advance, and seldom at a distance greater than $3 a$ from the tunnel face, where $a$ is the tunnel radius.

As the strength decreased, compressive radial stresses started to develop at the edges near the crown and invert (see Fig. 15). With a further decrease in the strength, an almost 
Fig. 14. Distribution of tangential stresses at the tunnel face: (a) $\sigma_{\mathrm{cm}} / p_{\mathrm{o}}=3.0$ (elastic); (b) $\sigma_{\mathrm{cm}} / p_{\mathrm{o}}=1.4 ;$ (c) $\sigma_{\mathrm{cm}} / p_{\mathrm{o}}=1.0$; (d) $\sigma_{\mathrm{cm}} / p_{\mathrm{o}}=0.8 ;(e) \sigma_{\mathrm{cm}} / p_{\mathrm{o}}=0.4$. (a)

41

37

(d)

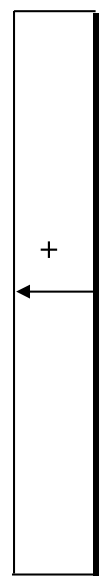

37

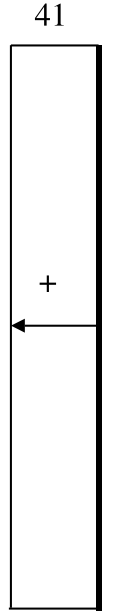

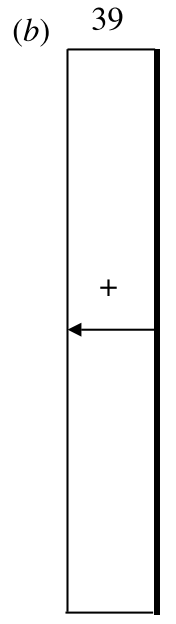

39

36

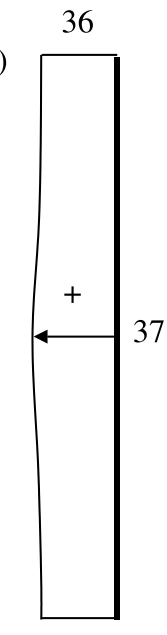

(c)

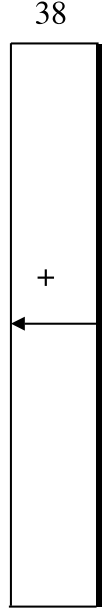

38

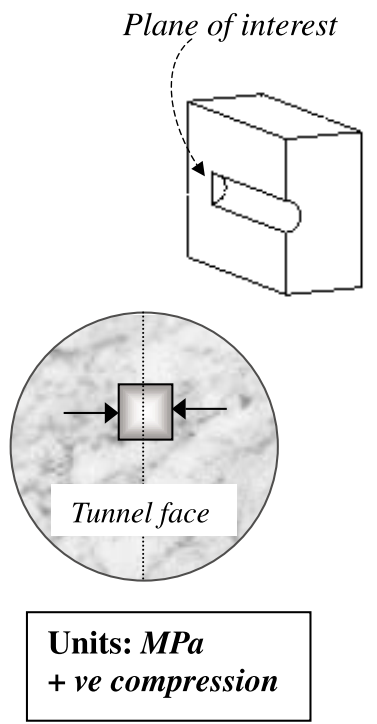

uniform distribution of compressive stress was observed. These results suggest that face stability may involve a fundamentally different mechanism of failure in strong and weak rock.

A summary of results is given in Fig. 16, which shows similar behaviour for the rock at the face centre and springline, where tensile stresses started to develop at a rock mass strength of about 1.0-1.5 times the in situ stress and elastic response was found at $\sigma_{\mathrm{cm}} / p_{\mathrm{o}}$ of about 2.0. The foregoing results are of practical importance for design engineers. In addition to controlling deformations, the temporary supporting system should be designed to resist the stress-induced instability of the tunnel. The existence of stress concentration at the crown and invert may lead to roof fall and floor heave in a weak rock mass or rock bursting in a high-strength rock mass.
Fig. 15. Distribution of radial stresses at the tunnel face: (a) $\sigma_{\mathrm{cm}} / p_{\mathrm{o}}=3.0$ (elastic); (b) $\sigma_{\mathrm{cm}} / p_{\mathrm{o}}=1.4 ;(c) \sigma_{\mathrm{cm}} / p_{\mathrm{o}}=1.0$; (d) $\sigma_{\mathrm{cm}} / p_{\mathrm{o}}=0.8 ;(e) \sigma_{\mathrm{cm}} / p_{\mathrm{o}}=0.4$.

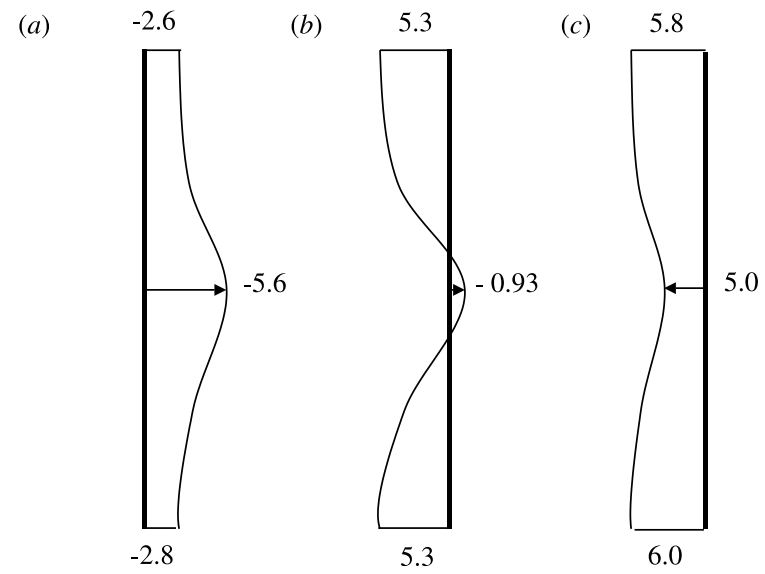

(d) $\quad 6.0$

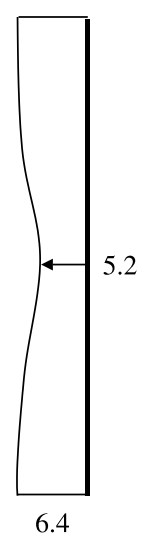

(e)

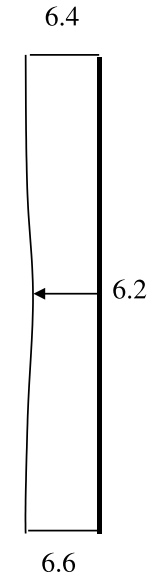

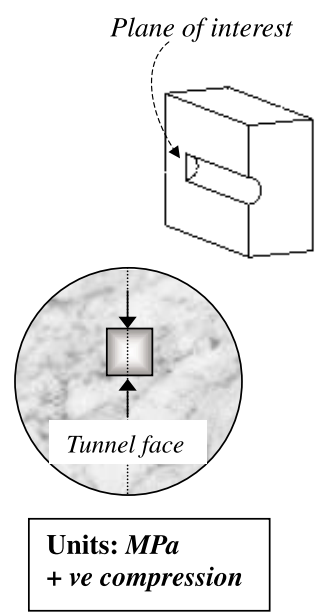

\subsection{The effect of face advance on the tangential stress distribution}

The final tangential stresses around the tunnel opening were presented in the previous section. The stresses developed at a plane strain cross section behind and at the tunnel face were also provided. During the face advance, however, the magnitude and orientation of the stresses keep changing until plane strain conditions are reached. The effect of face advance on the tangential stress changes is discussed in this section.

Tangential stresses at several cross sections along the tunnel are plotted in Figs. 17 and 18 for the crown and springline, respectively. At the tunnel crown, tangential stresses close to the face are higher than those at the plane strain cross section for poor to weak quality rock mass $\left(\sigma_{\mathrm{cm}} / p_{\mathrm{o}}=\right.$ $0.4-1.0$ ), with a significant stress increase of about $100 \%$ for $\sigma_{\mathrm{cm}} / p_{\mathrm{o}}=0.4$ at a distance of $5 \mathrm{~m}$ from the face. As the rock mass strength increased, a more uniform stress distribution was found along the tunnel. The practical significance of this observation is that the stress redistribution near the face due to tunnel excavation depends on the ratio of the rock mass strength to the in situ stress. Higher tangential stress 
Fig. 16. Relationship between rock mass strength and tangential stresses. ps, plane strain conditions.

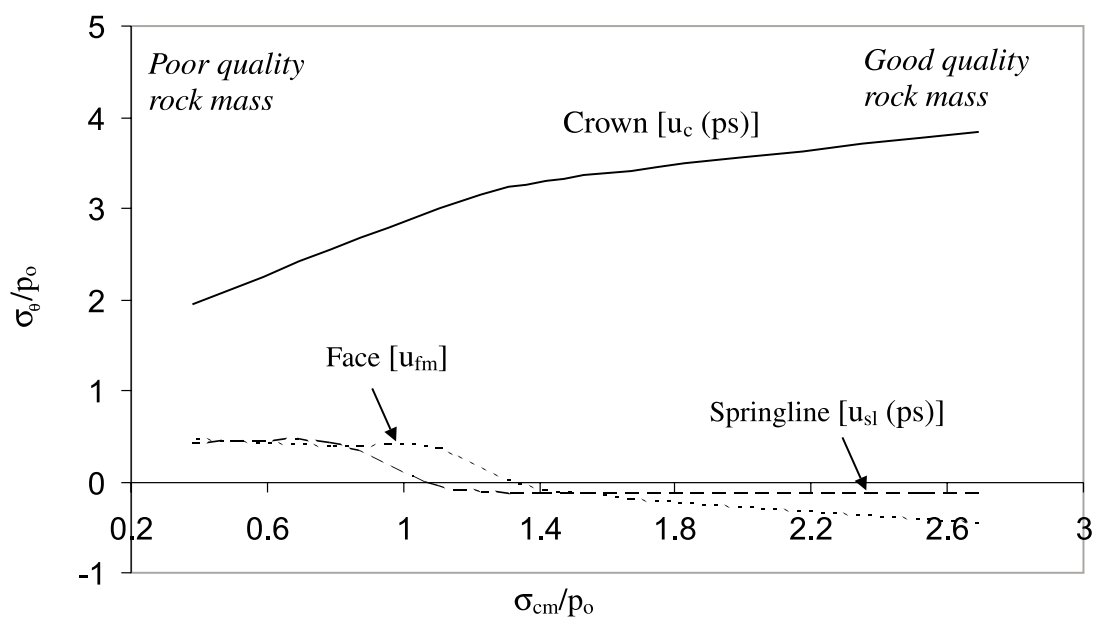

Fig. 17. Tangential stresses at the tunnel crown with distance from the tunnel face.

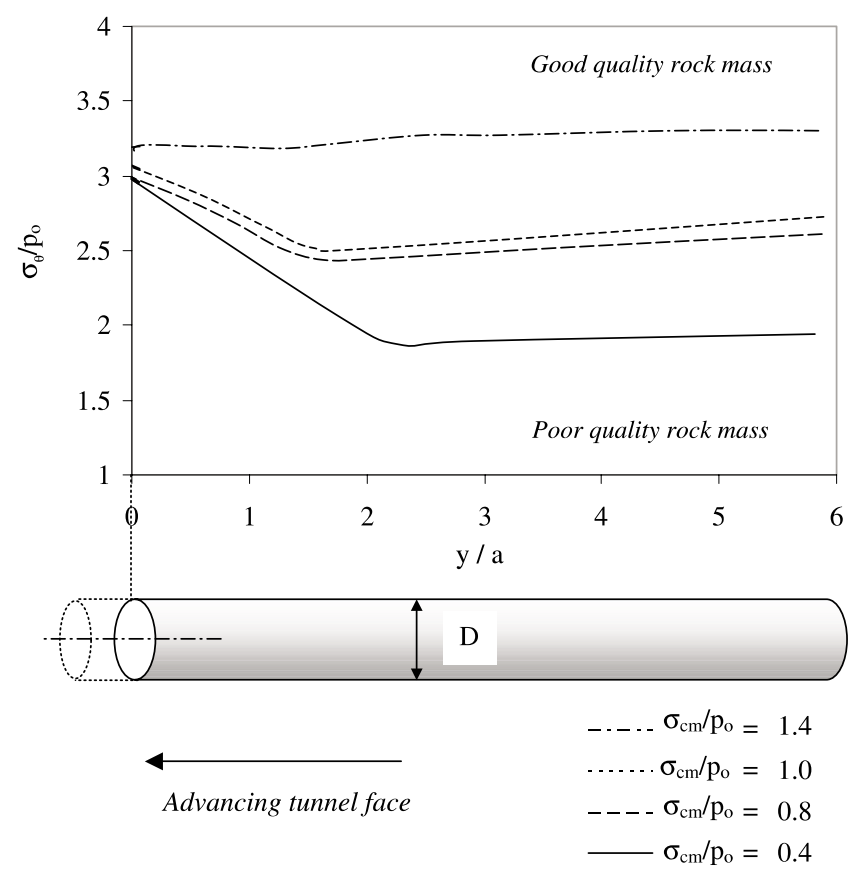

concentration occurs near the face for the relatively poor quality rock mass. Therefore, excavation in poor quality rocks should proceed with caution, and a temporary lining should be installed as close to the face as possible to avoid local instability at the tunnel crown.

At the tunnel springline a similar but less pronounced trend was found for poor to weak quality rock where the tangential stresses (compressive) increased near the face. For $\sigma_{\mathrm{cm}} / p_{\mathrm{o}}>1.0$, tensile stresses developed along the tunnel, with a significant increase of about $100 \%$ for $\sigma_{\mathrm{cm}} / p_{\mathrm{o}}=1.4$ as shown in Fig. 18. The implication of this finding is that, although stress levels developed at the springline are small compared with in situ stresses, tensile stresses can rapidly develop close to the face, which may lead to local instability and cracking along the springline if tensile stresses exceeded the tensile strength of the rock.
Fig. 18. Tangential stresses at the tunnel springline with distance from the tunnel face.

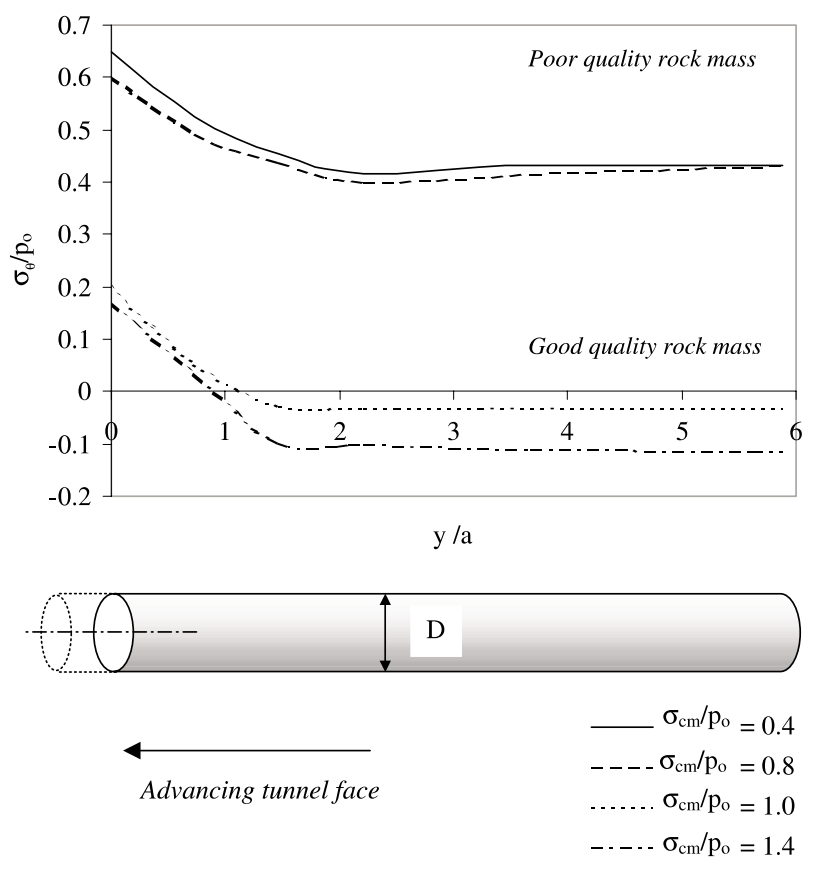

The distribution of tangential stresses around the tunnel circumference at different $y / a$ distances is shown in Fig. 19. The results are presented for two distinct cases of good and poor quality rock masses, respectively. For good quality rock (Fig. 19a), high compressive stresses generally developed at the tunnel crown, with a value of about $40 \mathrm{MPa}$. These stresses increased slightly with an increase in the distance from the tunnel face. This can be attributed to the reduction of the face contribution in resisting loads as we move away from the tunnel face. A tensile stress of about $3 \mathrm{MPa}$ was calculated at the tunnel springline. For poor quality rock (Fig. 19b), compressive stresses generally developed around the tunnel circumference. These stresses slightly increased as the tunnel face was approached. This behaviour was attributed to the development of a plastic zone at the tunnel face in poor quality rock. 
Fig. 19. Effect of face advance on the tangential stresses at the tunnel: $(a) \sigma_{\mathrm{cm}} / p_{\mathrm{o}}=3.0 ;(b) \sigma_{\mathrm{cm}} / p_{\mathrm{o}}=0.4$.

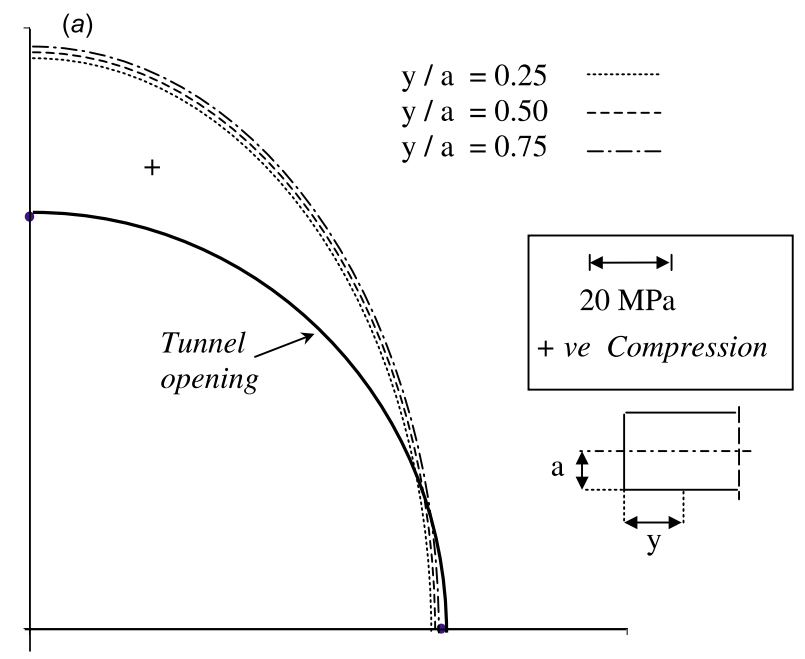

(b)

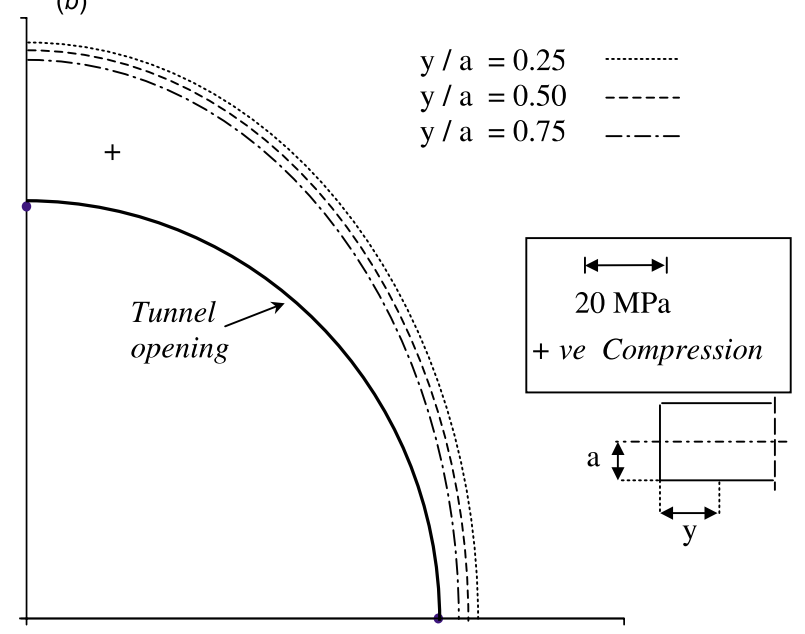

The results presented in Fig. 19 confirmed the tunnel response close to the face, discussed in the previous section, and suggest that a reliable estimate of the rock mass strength is essential in the case of large openings in weak rock to allow estimation of the ratio $\sigma_{\mathrm{cm}} / p_{\mathrm{o}}$ so that unexpected tunnel convergence and (or) instability can be avoided.

A different way of examining the effect of face advance on the developed stresses ahead of the advancing face is shown in Fig. 20 as a plot of the vertical stress $\left(\sigma_{v}\right)$ distribution along the tunnel centreline, ahead of the face. It may be argued that there is a stress concentration at a distance of about one tunnel radius ahead of the face, followed by a decrease of vertical stresses at the face. For a high-strength rock mass, this decrease in stress is rapid, and tensile stresses may develop. For a low-strength rock mass, however, a slight reduction was found, resulting in final compressive stresses equal to the initial vertical stress. Figure 20 also shows that the change of vertical stress with distance ahead of the tunnel face is small, which confirms the conclusion made in Sect. 5 and indicating that the size of excavation step adopted in the step-by-step incremental technique
Fig. 20. Distribution of vertical stresses ahead of the tunnel face.

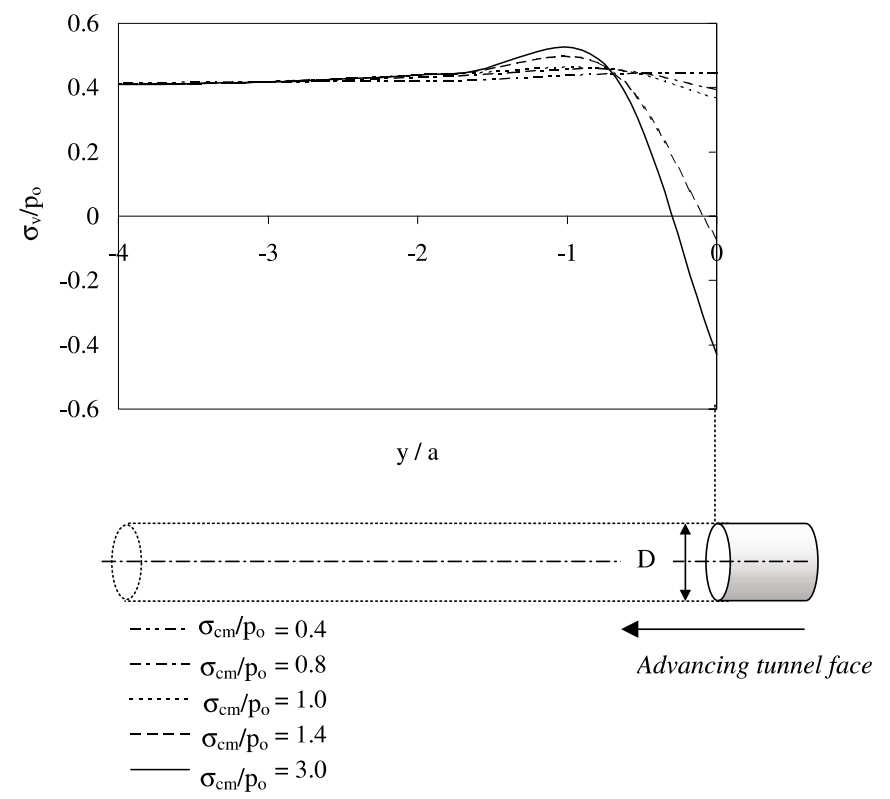

has a limited effect on the resulting radial behaviour of the tunnel.

\section{Plastic zone development}

To simplify the identification and 3D plotting of the plastic zone, elements with several (more than nine) plastic Gauss points are considered to become plastic and are plotted in Fig. 21. Using this method, the extent of the plastic zone is approximated to a distance of half an element width. Figure 21 shows the plastic zone developed around the tunnel face and circumference. To illustrate the extent of the plastic zone at the tunnel crown and haunches (at $45^{\circ}$ ), two cross sections were considered as shown in Figs. $22 a$ and $22 b$, respectively.

For the case of $\sigma_{\mathrm{cm}} / p_{\mathrm{o}}=1.4$, a plastic zone was uniformly distributed around the tunnel circumference near the tunnel haunches and extended along the excavated part of the tunnel up to a distance of about $10 \mathrm{~m}$ from the tunnel face. The extent of the plastic zone based on these results was about $4 \mathrm{~m}$ from the tunnel. For $\sigma_{\mathrm{cm}} / p_{\mathrm{o}}=1.0$, the distribution of the plastic zone was not uniform, such that plasticity concentrated at the tunnel haunches with a radius of about $8 \mathrm{~m}$ from the tunnel circumference and $4 \mathrm{~m}$ elsewhere. Local plasticity was observed at the tunnel face near the crown and invert.

As the rock mass strength decreased, the plastic zone developed around the tunnel opening followed the same pattern as that discussed in the previous paragraph. However, the radius of the plastic zone extended farther at the tunnel haunches to a distance of about $16 \mathrm{~m}$ from the tunnel circumference and increased to $8 \mathrm{~m}$ at the crown. A continuous plastic zone was found at the tunnel face, as shown in Fig. $21 b$.

It is evident from the previous results that the size of the plastic zone around the tunnel opening shows a dramatic increase, and a continuous plastic zone formed at the face when the uniaxial compressive strength of the rock mass 
Fig. 21. Plastic zone developed around the tunnel: $(a) \sigma_{\mathrm{cm}} / p_{\mathrm{o}}=1.4 ;(b) \sigma_{\mathrm{cm}} / p_{\mathrm{o}}=1.0 ;(c) \sigma_{\mathrm{cm}} / p_{\mathrm{o}}=0.8 ;(d) \sigma_{\mathrm{cm}} / p_{\mathrm{o}}=0.4$.

(a)

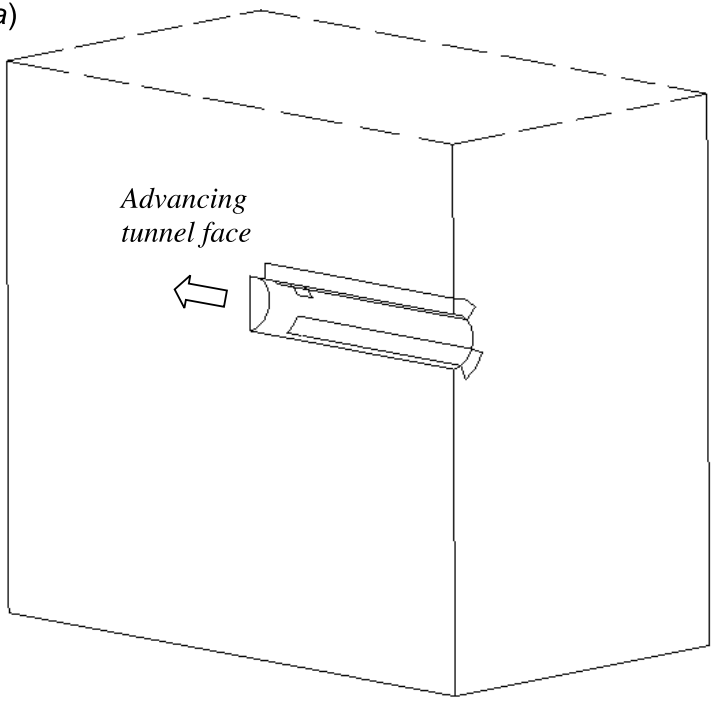

(b)

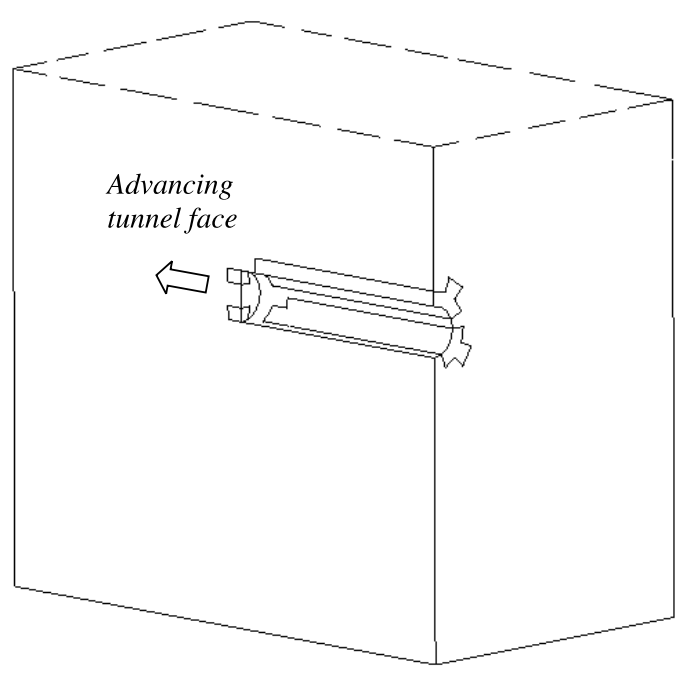

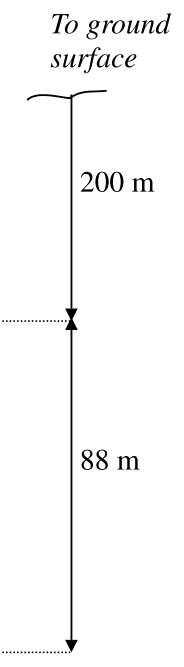

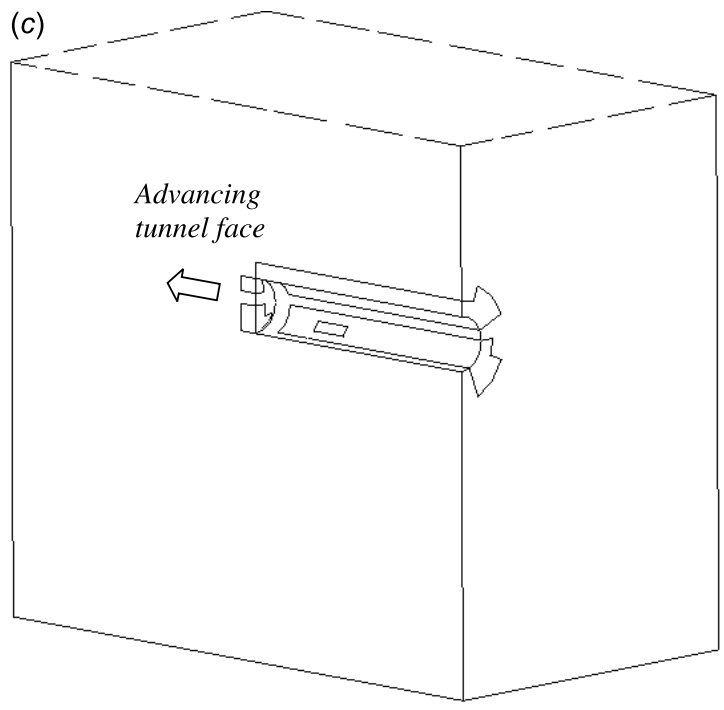

(d)

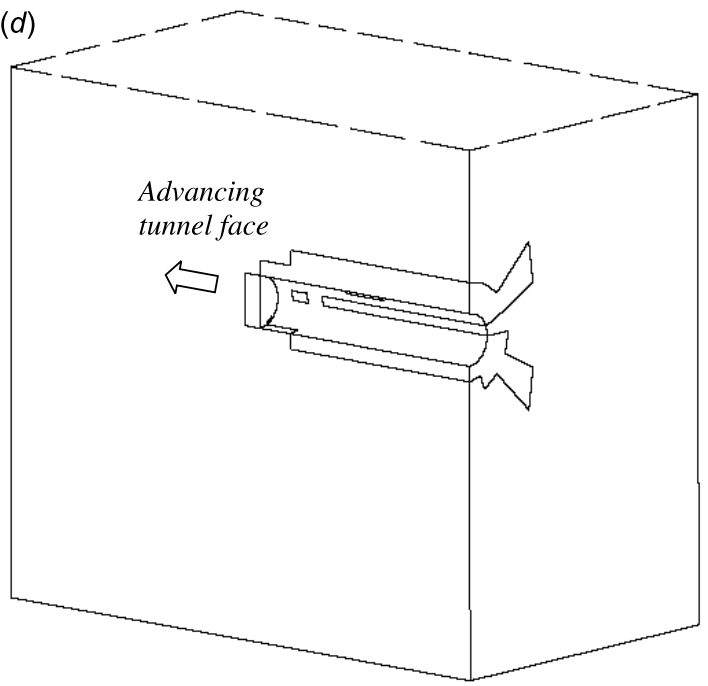

was about 0.4 . Unless adequate support is provided, the tunnel may be unstable under such conditions.

\section{Summary and conclusions}

The behaviour of a large-diameter tunnel in weak rock subjected to high horizontal stresses was investigated. The analysis allowed the computation of the complete stresses and deformation patterns and plastic zone development around the length of the tunnel and at the face.

For a high-strength rock mass, the calculated displacements are consistent with field observations from different case histories where outward movements were observed to occur at the crown and invert of the tunnel. In weak rocks, because of the development of the plastic zone, both the crown and invert are predicted to move inwards. Outside the plastic zone, however, the rock mass tends to move outwards because of the elastic response to high horizontal stresses. These displacement directions should be kept in mind when interpreting the results of field measurements.
It was observed that due to the tunnel excavation, a large amount of displacement has already occurred at the tunnel crown and springline ahead of the face. This observation must be taken into account when planning field instrumentation programs. Great care must also be taken in interpreting the displacement results (for example, to back-calculate the mass modulus of the rock) based on field measurements of tunnel convergence using measuring points inside the tunnel.

The plastic zones were concentrated at the tunnel haunches and extended along the excavated part of the tunnel up to a distance of about one tunnel diameter from the tunnel face. Adequate support at the face and springline is required when the ratio of rock mass strength to in situ stress falls below 0.4 , at which point a continuous plastic zone is formed.

Face stability involves fundamentally different mechanisms of failure in strong and weak rock. For the case of weak rock, stress concentration may lead to overstressing of the rock mass at the face, causing local instability and possibly failure. Strong rock may experience a different failure 
Fig. 22. Approximate extent of the plastic zone at $(a)$ the tunnel face and crown, and $(b)$ the haunches.
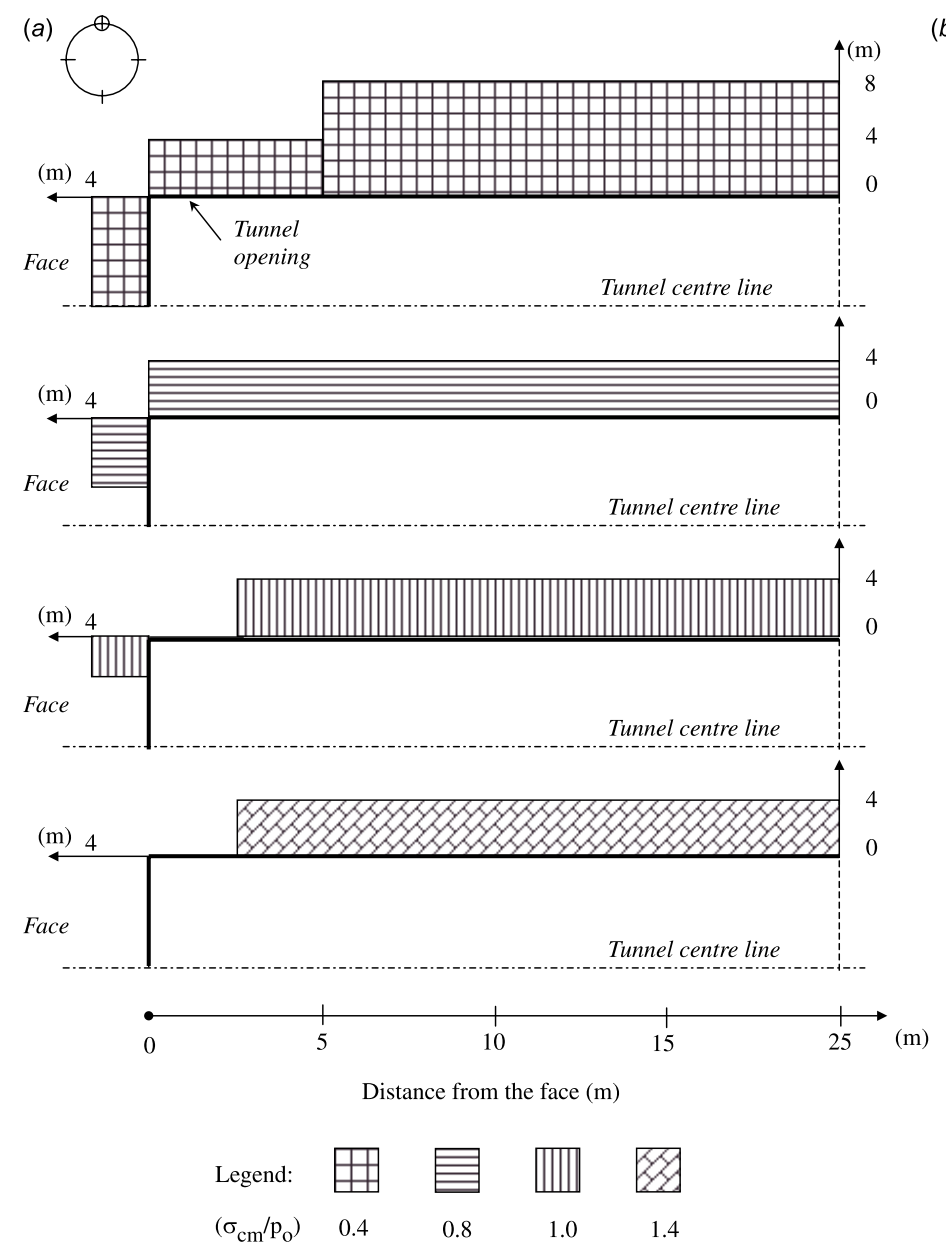

mechanism where tensile stresses may occur at the face, causing tensile fracture and rock bursting.

\section{Acknowledgements}

This research is supported by the Natural Sciences and Engineering Research Council of Canada (NSERC). Support in the form of an NSERC Post-graduate Scholarship (PGSB) and an Ontario Government Scholarship in Science and Technology (OGSST) are also acknowledged.

\section{References}

Abdel-Meguid, M. 2002. Selected three-dimensional aspects of tunnelling. Ph.D. thesis, University of Western Ontario, London, Ont.

Abdel-Meguid, M., Rowe, R.K., and Lo, K.Y. 2002. Effects of boundary locations on the finite element predictions for large openings in rock. In Proceedings of the 2nd Canadian Specialty Conference on Computing in Geotechnique, Winnipeg, Man., 28-30 April 2002. Canadian Geotechnical Society, Alliston, Ont. pp. 317-324.

Brown, P.T., and Booker, J.R. 1985. Finite element analysis of excavations. Computers and Geotechnics, 1(3): 207-220.

Gudehus, G. 1973. Elastoplstische stoffgleichungen für trockenen sand. Ingenieur-Archiv, 42, 245-258. (b)

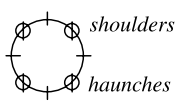

16
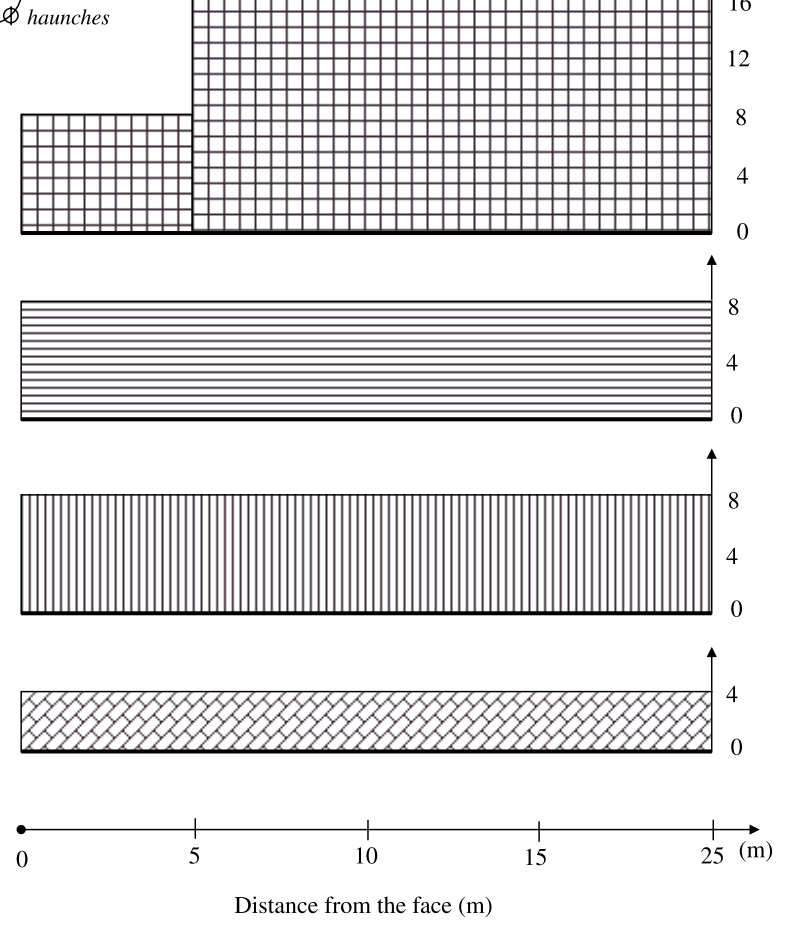

Hefny, A.M., and Lo, K.Y. 1999. Analytical solutions for stresses and displacements around tunnels driven in cross-anisotropic rocks. International Journal for Numerical and Analytical Methods in Geomechanics, 23(2):161-177.

Hoek, E., and Marinos, P. 1998. Predicting tunnel squeezing problems in weak heterogeneous rock masses. Tunnels and Tunnelling International, 32(11): 45-51.

Lade, P.V., and Duncan, J.M. 1975. Elasto-plastic stress-strain theory for cohesionless soils. Preceedings of the American Society of Civil Engineers (ASCE), 101, 1037-1053.

Lee, K.M. 1989. Prediction of ground deformations resulting from shield tunnelling in soft clays. Ph.D. thesis, University of Western Ontario, London, Ont.

Lo, K.Y. 1989. Recent advances in design and evaluation of performance of underground structures in rocks. Tunnelling and Underground Space Technology, 4(2): 171-185.

Lo, K.Y., Lukajic, B., and Ogawa, T. 1984. Interpretation of stressdisplacement measurements. In GEOTECH 84, Proceedings of the Session Sponsored by the Geotechnical Engineering Division, Atlanta, Ga., May 1984. American Society of Civil Engineers, New York. pp. 128-155.

Lo, K.Y., Ogawa, T., Sekiguchi, K., and Rowe, R.K. 1992. Large deformation and face instability in tunnelling through thick fault zones. Canadian Tunnelling Journal, 1: 77-96.

Martna, J. 1970. Rock bursting in the Sourva-Vietas Headrace tunnel. In Proceedings of the 1st International Congress of the International Association of Engineering Geology, Paris, France, 8-11 Sept. 1970. Vol. 2. Editions du B.R.G.M. pp. 1134-1139. 
Sakurai, S. 1983. Displacement measurements associated with the design of underground openings. In Field Measurements in Geomechanics: Proceedings of the 1st International Symposium, $\mathrm{Zu}$ rich, Switzerland, 5-8 Sept. 1983. Vol. 2. Edited by K. Kovari. A.A. Balkema, Rotterdam, The Netherlands. pp. 1163-1178.

Smith, I.M., and Griffiths, D.V. 1998. Programming the finite element method. 3rd ed. John Wiley, London, U.K.
Yuen, M.K., Erzinclioglu, A., Huang, H.S., and Somerville, N. 1992. Design of diversion tunnels: Niagara River hydraulic development. In Proceedings of the 45th Canadian Geotechnical Conference, Toronto, Ont., October 1992. BiTech Publishers Ltd., Richmond, B.C. 